\title{
Middle East and Southwest Asia Daily Precipitation Characteristics Associated with the Madden-Julian Oscillation during Boreal Winter ${ }^{\mathscr{A}}$
}

\author{
ANDREW HOELL \\ NOAA/Earth System Research Laboratory/Physical Sciences Division, \\ Boulder, Colorado \\ FOREST CANNON \\ Center for Western Weather and Water Extremes, Scripps Institution of Oceanography, \\ University of California, San Diego, La Jolla, California \\ MATHEW BARLOW \\ Department of Environmental, Earth and Atmospheric Sciences, University of Massachusetts \\ Lowell, Lowell, Massachusetts
}

(Manuscript received 5 February 2018, in final form 22 August 2018)

\begin{abstract}
The spatial and temporal evolution of Middle East and southwest Asia (MESW) precipitation characteristics and the associated atmospheric circulation during times in which tropical eastern Indian Ocean precipitation is either enhanced or reduced associated with the Madden-Julian oscillation (MJO) is assessed. Using multiple estimates of both the observed precipitation and the MJO during 1981-2016, the evolution of MESW precipitation characteristics throughout November-April is examined in terms of monthly precipitation accumulation on precipitation days, the number of precipitation days, and the number of extreme precipitation days. MJO phases 2-4, during which eastern Indian Ocean precipitation is enhanced, and MJO phases 6-8, during which eastern Indian Ocean precipitation is reduced, are related, with significant decreases and increases in the number of precipitation days across MESW, respectively. The patterns of precipitationday changes between MJO phases undergo noteworthy spatial and temporal evolutions across the boreal cold season that are influenced by the interaction between Rossby wave forcing by the MJO and seasonal changes in both the upper-level jet and moisture over the region. During December-January, the changes in precipitation days are found primarily over northern MESW, while during February-March, the changes in precipitation days are found primarily over southern MESW. Although the results identify an important sensitivity in the number of precipitation days over the MESW related to the MJO, the same sensitivity is not apparent in terms of the number of extreme precipitation days and, in particular, the amount of precipitation on a precipitation day.
\end{abstract}

\section{Introduction}

During November-April, phases of the Madden-Julian oscillation (MJO; Madden and Julian 1972, 1994; Zhang 2005) that directly modify tropical eastern Indian Ocean

Supplemental information related to this paper is available at the Journals Online website: https://doi.org/10.1175/JCLID-18-0059.s1.

Corresponding author: Andrew Hoell, andrew.hoell@noaa.gov precipitation $^{1}$ are closely related with Middle East and southwest Asia (MESW) precipitation anomalies (Fig. 1) (e.g., Barlow et al. 2005; Nazemosadat and Ghaedamini 2010; Barlow 2011; Hoell et al. 2013 and references herein). Previous research has considered either November-April in aggregate or smaller areas within MESW, and has found that phases $2-4$ of the MJO, during which tropical eastern Indian Ocean precipitation is

\footnotetext{
${ }^{1}$ As measured by the all-season real-time multivariate MJO index of Wheeler and Hendon (2004).
} 
(a) MJO2-4 OLR Change

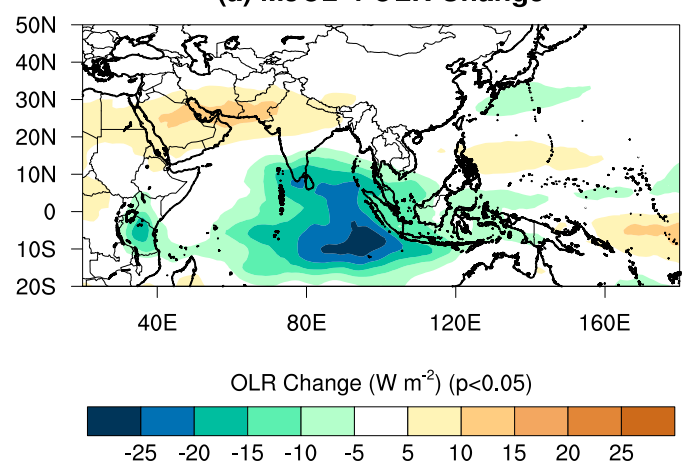

(c) MJO2-4 Precipitation Change

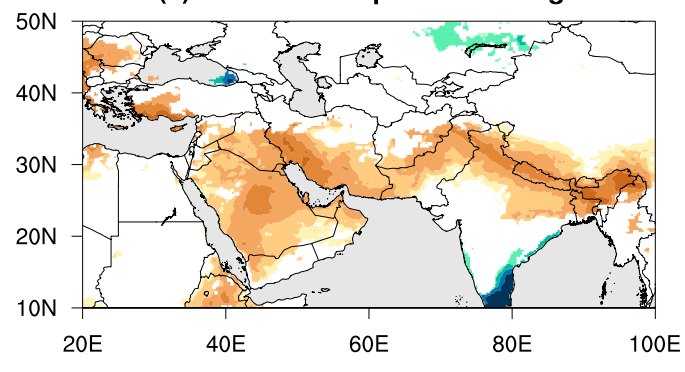

Precipitation Change $\left(10 \times \mathrm{mm} \mathrm{d}^{-1}\right)(p<0.05)$

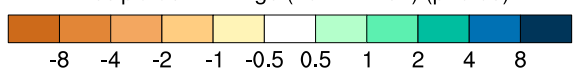

(b) MJO6-8 OLR Change

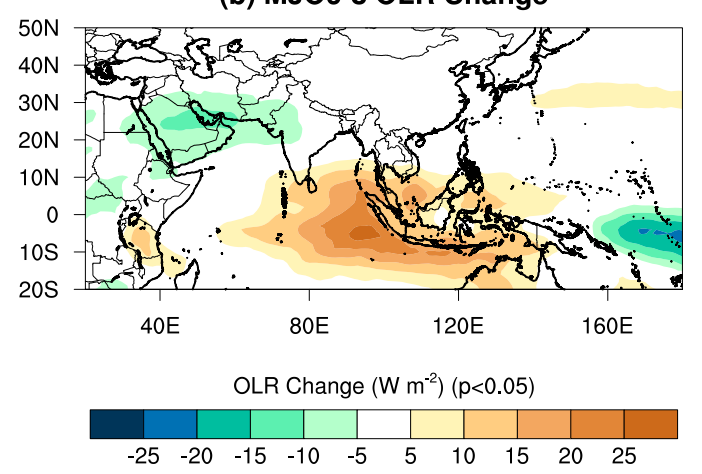

(d) MJO6-8 Precipitation Change

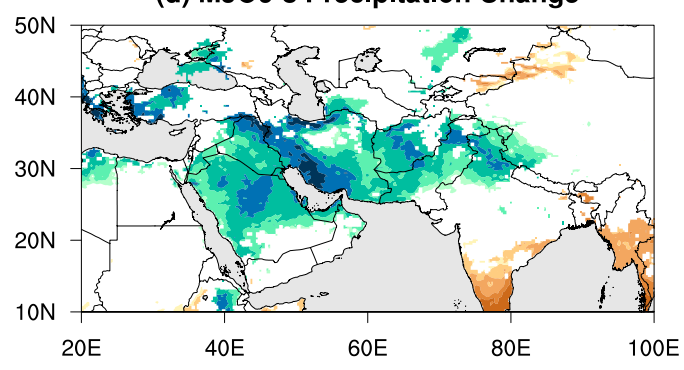

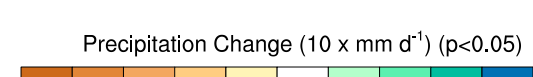

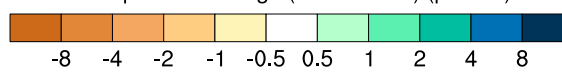

FIG. 1. Average daily change in (a),(b) OLR $\left(\mathrm{W} \mathrm{m}^{-2}\right)$ and (c),(d) precipitation (mm day ${ }^{-1}$ ) when (left) MJO2-4 and (right) MJO6-8 criteria are met during November-April 1981-2016 using RMM. Changes are significant at $p<0.05$.

enhanced (Fig. 1a), is related with statistically significant decreases of MESW precipitation (Fig. 1c) while phases 6-8 of the MJO, during which tropical eastern Indian Ocean precipitation is reduced (Fig. 1b), is related with statistically significant increases of MESW precipitation (Fig. 1d). Knowledge of the MJO and MESW relationship during November-April has in turn provided valuable insights into potential MESW precipitation prediction skill during the region's rainy season (Barlow et al. 2005; Hoell et al. 2012).

While previous research has shown a robust relationship between the MJO and MESW precipitation during the November-April season, how the relationship changes over the course of the season and how the relationship is expressed through changes in precipitation frequency and intensity has so far only received limited attention. This knowledge gap thus limits the predictive information that the MJO offers for MESW precipitation on subseasonal time scales. With the aim of narrowing this gap, we pursue a systematic examination of the relationships between the MJO and daily precipitation accumulation during each month of the November-April season over MESW, using multiple observed precipitation estimates and multiple estimates of the MJO during 1981-2016. We focus upon previously unexplored changes in the number of precipitation days per month, changes in the number of extreme precipitation days per month, and changes in monthly precipitation accumulation on precipitation days over the MESW.

While the MJO is responsible for widespread precipitation impacts, notably over regions that include East Africa (Pohl and Camberlin 2006; Barlow 2011; Berhane and Zaitchik 2014), West Africa (Berhane et al. 2015; Sossa et al. 2017), southern Africa (Pohl et al. 2007), Australia (Wheeler et al. 2009), North America (e.g., Jones 2000; Jones and Carvalho 2012, 2014; Klotzbach et al. 2016), and South America (e.g., De Souza and Ambrizzi 2006; Shimizu et al. 2017; Shimizu and Ambrizzi 2016; Alvarez et al. 2016), the MJO arguably exerts its strongest impacts over the MESW. Barlow et al. (2005) were the first to identify the MJO and MESW relationship, and found that enhanced tropical eastern Indian Ocean precipitation associated with the MJO is related with reduced MESW precipitation, and that reduced tropical eastern Indian Ocean precipitation associated with the MJO is related with enhanced MESW precipitation for the entire 
November-April season. Additionally, Barlow et al. (2005) found that the 10 wettest days for Afghanistan from 1979 to 1985 occurred during the enhancing phase of the MJO.

Focusing solely on southern Iran and the Persian Gulf region of MESW, Nazemosadat and Ghaedamini (2010) and Nazemosadat and Shahgholian (2017) explored the relationship between the regional precipitation and the MJO during the November-April season. Nazemosadat and Ghaedamini (2010) found southern Iran seasonal precipitation to be especially sensitive to changes in tropical eastern Indian Ocean precipitation associated with the MJO. Nazemosadat and Shahgholian (2017) explored daily precipitation extremes over Iran, and found that heavy precipitation days are most common during December and January during phase 8 of the $\mathrm{MJO}$, one of the phases in which tropical eastern Indian Ocean precipitation is reduced.

The dynamical mechanisms underlying the MJO and MESW precipitation relationship have been studied in some detail. Changes in eastern Indian Ocean and Maritime Continent precipitation associated with the MJO result in changes in tropical diabatic heating, which in turn force a Gill-Matsuno-type response (Gill 1980; Matsuno 1966) over the MESW (Barlow et al. 2005, 2007; Hoell et al. 2012) that is modified by the mean wind (Barlow 2011). The Gill-Matsuno-type response over the MESW is defined by the presence of anomalous baroclinic Rossby waves that extend across southern Asia, in which the sign of the anomalous upper-tropospheric circulation is opposite that of the anomalous lower-tropospheric circulation (Hoell et al. 2012). Enhanced tropical eastern Indian Ocean precipitation associated with the MJO is related with anomalous upper-tropospheric anticyclonic circulation over MESW, while reduced tropical eastern Indian Ocean precipitation associated with the MJO is related with anomalous upper-tropospheric cyclonic circulation over MESW. The anomalous baroclinic Rossby waves excited over MESW by the MJO interact with the uppertropospheric mean wind to produce thermodynamically forced vertical motions and therefore precipitation anomalies (Barlow et al. 2005, 2007; Hoell et al. 2012). The interaction of warm-core upper-tropospheric anomalous anticyclonic circulations with the mean wind results in cold temperature advection, anomalous subsidence, and therefore, reduced precipitation over MESW. By contrast, the interaction of cold-core upper-tropospheric anomalous cyclonic circulations with the mean wind results in warm temperature advection, anomalous ascent, and therefore, enhanced precipitation over MESW.

While the relationship between MESW circulation and the MJO has only recently been identified, it should be noted that research dating back to the 1980s has implied relationships between MESW circulation and changes in tropical eastern Indian Ocean precipitation. Lau and Chan (1983) were among the first to identify an out-of-phase relationship between eastern Indian Ocean precipitation and precipitation over western Asia. Liebmann (1987) provided context to this relationship identified by Lau and Chan (1983) by showing that enhanced eastern Indian Ocean and Maritime Continent precipitation is related to precipitation-reducing anticyclonic circulation over MESW.

The MESW and MJO precipitation relationships during November-April have been used to better understand the nature of extreme precipitation events over the entire MESW region (Barlow et al. 2005; Hoell et al. 2012) and for areas within the region, such as southern Iran and the nearby Persian Gulf (Nazemosadat and Ghaedamini 2010; Nazemosadat and Shahgholian 2017), and the Karakorum of northeastern Pakistan (Cannon et al. 2017). Both Barlow et al. (2005) and Hoell et al. (2012) suggest that multiday precipitation events that resulted in notable flooding over the MESW were related to reduced tropical eastern Indian Ocean precipitation associated with the MJO, with the former study focusing upon 12-13 April 2002 and the latter study focusing upon late December 2007. Over southern Iran, Nazemosadat and Shahgholian (2017) found that the occurrences of extreme precipitation days over southern Iran increased during times in which eastern Indian Ocean precipitation was reduced associated with the MJO, especially so during the months of December and January. Over the Karakorum, Cannon et al. (2017) found no clear links between the MJO and a modification in the frequency of extreme precipitation events during November-April. However, Cannon et al. (2017) did identify key differences in the forcing of Karakorum precipitation as a result of shifting contributions between the atmospheric dynamics and atmospheric moisture between MJO phases.

On seasonal time scales, El Niño-Southern Oscillation (ENSO) is closely related with MESW precipitation (Barlow et al. 2002; Mariotti 2007; Barlow et al. 2007; Hoell and Funk 2013; Hoell et al. 2013, 2014, 2015b, 2017, 2018). During November-April, La Niña is on average related with reduced MESW precipitation while El Niño is on average related with enhanced MESW precipitation. The ENSO state may therefore impact the relationship between the MJO and MESW precipitation characteristics on subseasonal time scales, as ENSO has been found to do for the entire November-April season in aggregate (Cannon et al. 2017). We do not condition our analyses on the relationship between MESW precipitation characteristics and the MJO on ENSO state because of the small resulting sample size, but we 
recognize that the superposition of MJO and ENSO forcing may be relevant for MESW subseasonal precipitation prediction skill.

While all of the aforementioned studies relating MESW precipitation and the MJO provide valuable insights, their focus on either the entire NovemberApril season or on specific areas within the region limit their ability to speak to the spatial and temporal evolution of the MESW and MJO relationship during the course of November-April. Some of the previous literature has strongly implied that these spatial and temporal changes indeed exist. For example, a comparison between the precipitation responses over southern Iran (Nazemosadat and Shahgholian 2017) and the Karakorum (Cannon et al. 2017) to the MJO suggest important subregional spatial precipitation features related to the MJO, despite westerly disturbances serving as the primary driver of precipitation regionally during winter. Additionally, the preference for extreme daily precipitation over southern Iran associated with the MJO during December and January suggests important temporal variability of the relationship (Nazemosadat and Shahgholian 2017).

With the goal of enhancing the predictive information that the MJO offers for MESW precipitation, we examine the spatial and temporal evolution of MESW precipitation associated with the MJO throughout the region's November-April rainy season during 19812016. The objective of section 2 is twofold. First, we introduce the data used in this study, highlighted by daily precipitation and MJO estimates. Second, we describe the methods used to better understand the precipitation accumulation on precipitation days, changes in the number of precipitation days, and changes in the number of extreme precipitation days during enhanced and reduced periods of tropical eastern Indian Ocean precipitation during each month of November-April associated with the MJO. In section 3, we present the changes in precipitation characteristics associated with the MJO in terms of spatial patterns and the related atmospheric circulation. In section 4 , we provide a summary and a brief discussion.

\section{Data and methods}

\section{a. Data}

Observed daily precipitation and atmospheric circulation related with the MJO are examined. Observed precipitation estimates over land are based on three sources: the Climate Hazards Group Infrared Precipitation with Stations (CHIRPS), the Climate Hazards Group Infrared Precipitation (CHIRP), and the
Climate Prediction Center Unified Gauge-Based Analysis of Daily Precipitation (CPC-Unified). Atmospheric circulation is based on the ERA-Interim (Dee et al. 2011).

CHIRPS and CHIRP, both on a $0.05^{\circ} \times 0.05^{\circ}$ latitude-longitude fixed grid during 1981-2016, are constructed similarly (Funk et al. 2015). CHIRP daily precipitation estimates are constructed using infrared cold cloud duration observations from five satellite products. CHIRPS daily precipitation estimates are constructed by blending CHIRP with an available array of station precipitation. The sources of CHIRPS station precipitation observations include the Global Historical Climate Network, the Global Summary of the Day, the World Meteorological Organization's Global Telecommunication System, the Southern African Science Service Centre for Climate Change and Adaptive Land Management, and arrays of precipitation made available by national and international agencies. Information related to uncertainty of both CHIRPS and CHIRP precipitation estimates are unavailable at this time.

The CPC-Unified daily precipitation estimate on a $0.5^{\circ} \times 0.5^{\circ}$ latitude-longitude fixed grid during 19812016 is constructed from only station data (Chen et al. 2008). Data sources for the CPC-Unified precipitation include Global Historical Climate Network, the Global Summary of the Day, the World Meteorological Organization's Global Telecommunication System, and national and international agencies. Features of the CPC-Unified precipitation include the consideration of orography and many quality control techniques, which include comparisons with satellite precipitation observations and model forecasts. The CPC-Unified precipitation product does not produce uncertainty estimates of precipitation.

Our analyses rely primarily upon CHIRPS, since CHIRPS can provide precipitation estimates over regions in which station observations are sparse, such as MESW, upon which we focus this analysis (Hoell et al. 2014, 2017). Nonetheless, we make regional comparisons between CHIRPS, CHIRP, and CPC-Unified to test the robustness of the results.

Estimates of MJO properties are drawn from the all-season real-time multivariate MJO index (RMM; Wheeler and Hendon 2004) and the all-season outgoing longwave radiation-based MJO index (OMI; Kiladis et al. 2014). RMM and OMI utilize broadly similar methodologies, but consider different variables, to estimate the MJO. RMM is described by a pair of indices, RMM1 and RMM2, which are calculated by projecting daily data onto the leading two combined empirical orthogonal functions of daily $15^{\circ} \mathrm{S}-15^{\circ} \mathrm{N}$ zonal wind at 850 and $200 \mathrm{hPa}$ from the NCEP-NCAR Reanalysis- 1 
(a) RMM December 2001 - February 2002 Phase 7 (Western Pacific) Phase 6

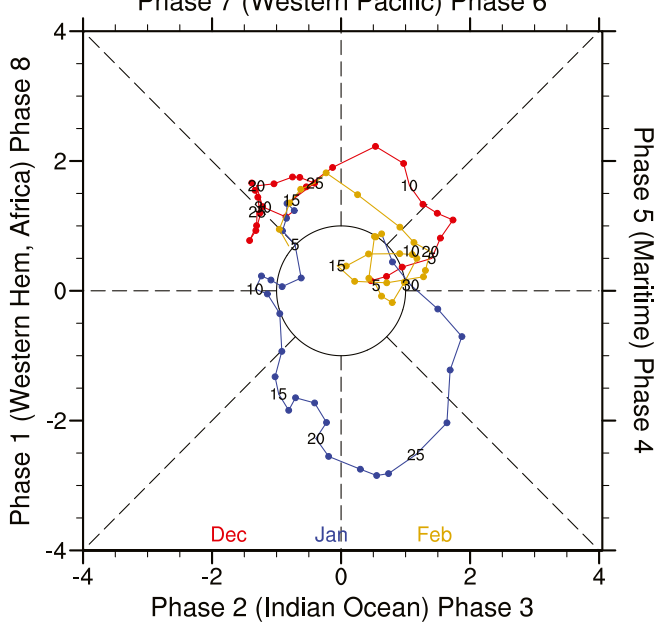

(b) OMI December 2001 - February 2002 Phase 7 (Western Pacific) Phase 6

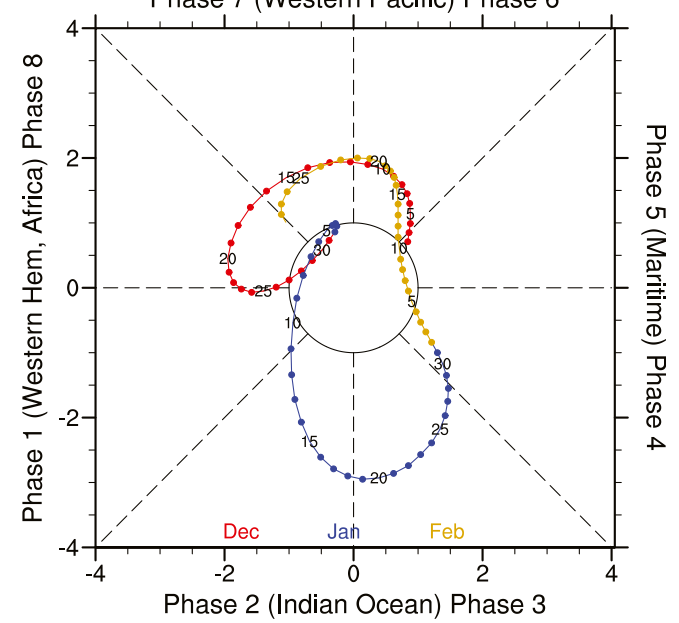

FIG. 2. MJO phase diagrams during December 2001-February 2002 constructed using (a) RMM and (b) OMI.

(Kalnay et al. 1996) and daily outgoing longwave radiation (OLR; Liebmann and Smith 1996) with the annual cycle and components of the interannual variability removed. OMI is also described by a pair of indices, which are calculated by projecting daily data onto the leading two empirical orthogonal functions of daily $20^{\circ} \mathrm{S}-20^{\circ} \mathrm{N}$ OLR (Liebmann and Smith 1996) filtered to exclude periods outside of 20-96 days.

Both RMM and OMI are oftentimes visualized in a two-dimensional phase space since the two indices that describe RMM and OMI demonstrate a lead-lag behavior. An example of MJO behavior estimated by
RMM and OMI for December 2001-February 2002 is shown in their respective phases spaces (Fig. 2). Counterclockwise traces of RMM and OMI around the origins indicate eastward propagation of the $\mathrm{MJO}$ while the distance of the trace from the origin indicates the magnitude of the MJO. At any time the MJO is in one of eight phases, which are defined based upon the position of enhanced precipitation over Africa, the Indian Ocean, the Maritime Continent, and the western Pacific (see axis labels on the MJO phase diagrams in Fig. 2).

While RMM and OMI suggest broadly similar MJO behavior during December 2001-February 2002 (Fig. 3),
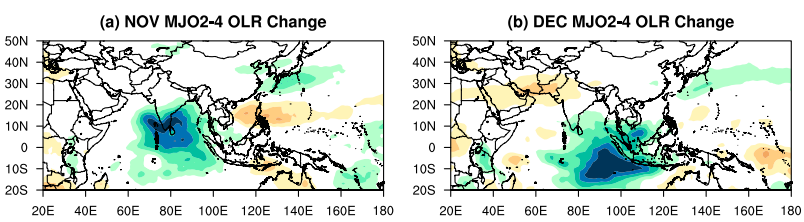

(c) JAN MJO2-4 OLR Change

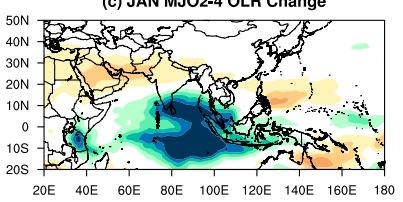

(e) MAR MJO2-4 OLR Change

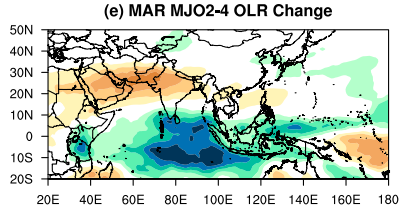

(d) FEB MJO2-4 OLR Change

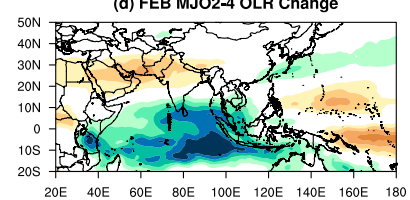

(f) APR MJO2-4 OLR Change

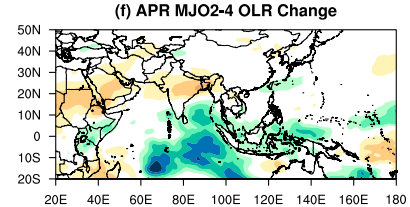

(g) NOV MJO6-8 OLR Change

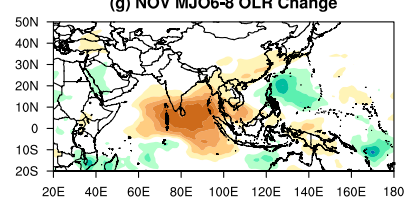

(i) JAN MJO6-8 OLR Change

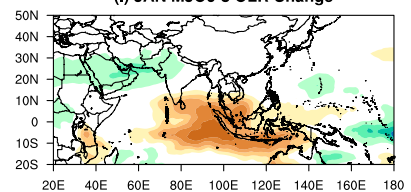

(k) MAR MJO6-8 OLR Change

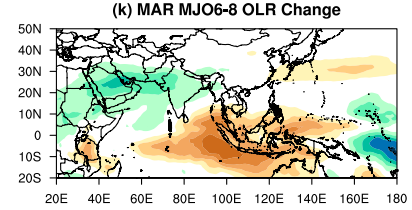

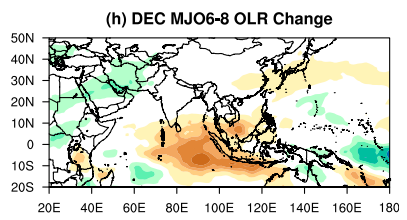

(i) FEB MJO6-8 OLR Change

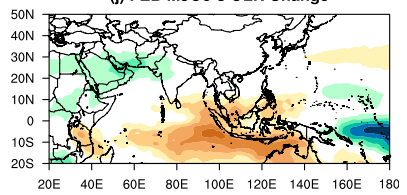

(I) APR MJO6-8 OLR Change

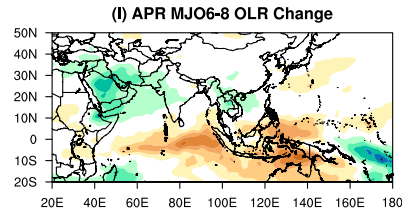

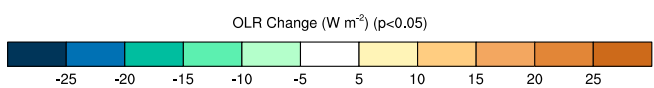

FIG. 3. The 1981-2016 daily OLR change ( $\mathrm{W} \mathrm{m}^{-2}$ ) when (a)-(f) MJO2-4 and (g)-(l) MJO6-8 criteria are met using RMM. Changes are significant at $p<0.05$. 
TABLE 1. Number of days that qualify as MJO2-4, MJO6-8, and neither MJO2-4 nor MJO6-8 in RMM.

\begin{tabular}{lrrrrrr}
\hline \hline & Nov & Dec & Jan & Feb & Mar & Apr \\
\hline MJO2-4 & 132 & 132 & 137 & 136 & 149 & 89 \\
MJO6-8 & 83 & 116 & 157 & 189 & 162 & 83 \\
Neither & 865 & 868 & 822 & 692 & 805 & 908 \\
Total & 1080 & 1116 & 1116 & 1017 & 1116 & 1080 \\
\hline
\end{tabular}

Kiladis et al. (2014) has shown that circulation-based (e.g., RMM) and OLR-based (e.g., OMI) MJO estimates can lead us to draw different conclusions. Our analyses herein are not sensitive to the MJO estimate used, as evidenced by parallel analyses shown within the manuscript and in the online supplemental material. Results generated using RMM are shown in the manuscript since RMM is updated in real time and has been so widely adopted, while results generated using OMI are shown in the online supplemental material.

\section{b. Methods}

Toward examining changes in MESW characteristics during times in which eastern Indian Ocean precipitation is either enhanced or reduced according to MJO phase, we first identify such days using OLR as a proxy for tropical precipitation. During November-April in aggregate (Fig. 1 and Fig. S1 in the online supplemental material) and for each November-April month (Figs. 3 and S2), phases 2-4 of the MJO (MJO2-4) are related with enhanced eastern Indian Ocean precipitation, and phases 6-8 of the MJO (MJO6-8) are related with reduced eastern Indian Ocean precipitation. To ensure that the MJO is of noteworthy magnitude in order to provide a consistent atmospheric forcing, and to account for the possible lag in the atmospheric teleconnection between the tropics and MESW, we require that the MJO remain in phases $2-4$ or phases $6-8$ and have a magnitude of greater than one for at least the previous 5 days for a given day to qualify as MJO2-4 or MJO6-8, respectively. A 5-day lag follows Hoell et al. (2013). Days that qualify as neither MJO2-4 nor MJO6-8 are considered inactive MJO for the purposes of this analysis.

For days that qualify as $\mathrm{MJO} 2-4, \mathrm{MJO}-8$, and inactive $\mathrm{MJO}$, we calculate monthly precipitation characteristics and the associated atmospheric circulation. Precipitation characteristics considered are accumulation on precipitation days, changes in the number of precipitation days, and the number of extreme precipitation days. Atmospheric circulation is assessed in terms of $200-\mathrm{hPa}$ geopotential height, $500-\mathrm{hPa}$ vertical velocity, vertically integrated moisture flux, and vertically integrated moisture flux divergence. Precipitation characteristics and the atmospheric circulation during inactive MJO serve as the
TABLE 2. Number of days that qualify as MJO2-4, MJO6-8, and neither MJO2-4 nor MJO6-8 in OMI.

\begin{tabular}{lrrrrrr}
\hline \hline & Nov & Dec & Jan & Feb & Mar & Apr \\
\hline MJO2-4 & 138 & 101 & 185 & 154 & 108 & 115 \\
MJO6-8 & 115 & 162 & 143 & 126 & 168 & 108 \\
Neither & 827 & 853 & 778 & 737 & 840 & 857 \\
Total & 1080 & 1116 & 1116 & 1017 & 1116 & 1080 \\
\hline
\end{tabular}

control by which the changes during days that qualify as MJO2-4 and MJO6-8 are compared. A precipitation day is defined to occur when daily precipitation exceeds $1 \mathrm{~mm}$. An extreme precipitation day at each grid point or regional average is defined to occur when daily precipitation falls in the 90th percentile on a precipitation day.

Though the number of days that qualify as MJO2-4, MJO6-8, or inactive MJO are somewhat different using RMM and OMI (cf. Tables 1 and 2), the spatial and regional precipitation characteristics calculated using both RMM and OMI are very similar. The likely reason behind the differences in days that qualify is that the OMI provides a smoother estimate of the MJO than RMM. It is important to note that there is little sensitivity in our results to the number of antecedent days required to be in MJO2-4 and MJO6-8, likely because of the persistence time scale of the MJO due to its slow propagation.

A bootstrapping approach is used to establish confidence intervals and to determine whether changes in characteristics during MJO2-4 or MJO6-8 are statistically different at the 5\% level from inactive MJO periods. Random samples, corresponding to the number of days that qualify as either MJO2-4 or MJO6-8, are drawn from the population of inactive MJO. The random samples are averaged and the process is repeated 10000 times to build a distribution. The $2.5 \%$ and $97.5 \%$ confidence levels are identified from this distribution, corresponding to a two-sided $p$ value of 0.05 .

\section{Results}

\section{a. MESW precipitation characteristics during inactive $M J O$}

To establish a baseline from which changes in MESW precipitation characteristics during $\mathrm{MJO} 2-4$ and MJO68 can be compared, we begin with an examination of the spatiotemporal variations in the number of precipitation days, the number of extreme precipitation days, and the amount of precipitation that falls on a precipitation day during inactive MJO. The number of precipitation days across MESW during inactive MJO varies widely in space and time, from just a handful of precipitation days during November to precipitation every second or third day over the Caucasus and the eastern slopes of High 
(a) NOV Precipitation Days

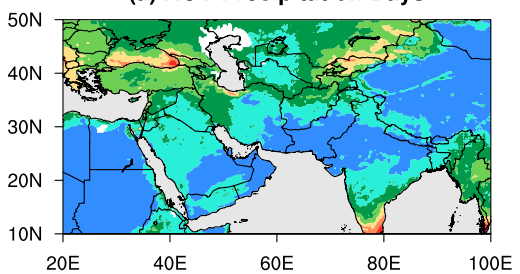

(d) FEB Precipitation Days

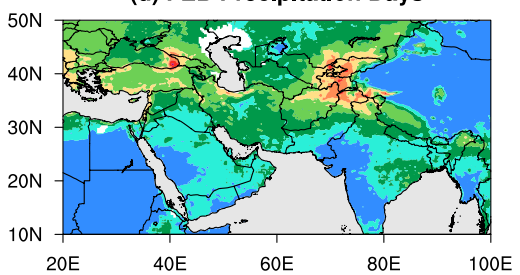

(b) DEC Precipitation Days

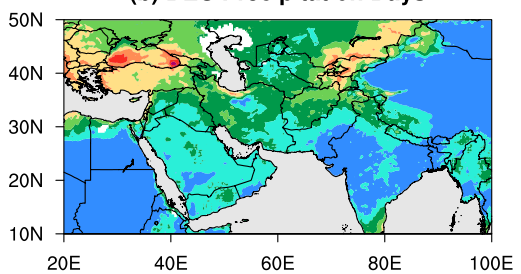

(e) MAR Precipitation Days

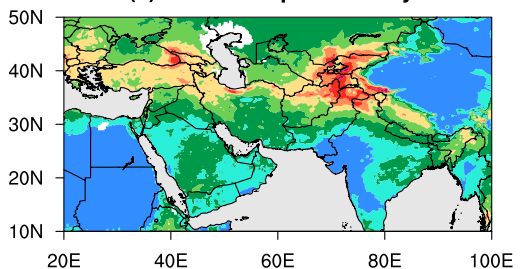

(c) JAN Precipitation Days

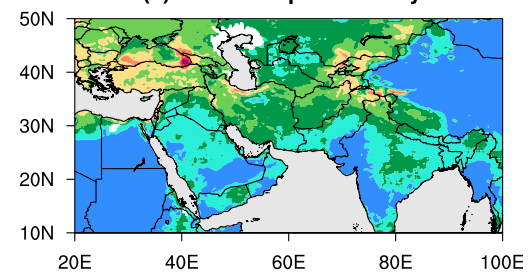

(f) APR Precipitation Days

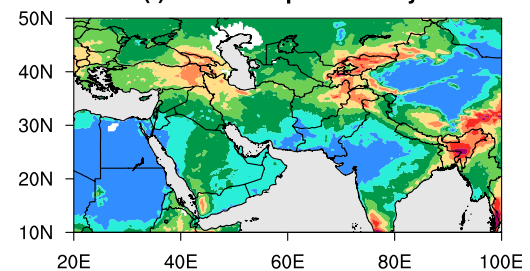

Days With Precipitation When Neither MJO2-4 Nor MJO6-8 Are Met

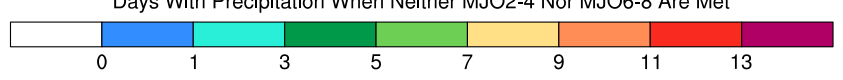

FIG. 4. Average number of precipitation days when neither MJO2-4 nor MJO6-8 criteria are met.

Asia during March (Fig. 4). November is the month during which the fewest precipitation days are observed regionwide, and the number of precipitation days increases by about $50 \%$ during December-February north of $30^{\circ} \mathrm{N}$. The greatest number of precipitation days are typically observed during March across the MESW, most notably along a zonal band from Turkey eastward through northern Iran, northern Afghanistan, and the mountains of High Asia that encircle western China. The number of precipitation days during April is still noteworthy, rivaling the pattern and magnitude observed during February throughout much of the MESW.
The number of extreme precipitation days across the MESW during inactive MJO also varies widely in space and time (Fig. 5), but somewhat surprisingly only partially follows the spatiotemporal evolution of the number of precipitation days during the region's rainy season (cf. Figs. 4 and 5). The pattern of extreme precipitation days becomes established over MESW in December, and that pattern evolves during January and February, as highlighted by a general shift to the south and east. March is the month during which the greatest number of extreme precipitation days are observed over the MESW, and also corresponds to the month with the (a) NOV Extreme P Days

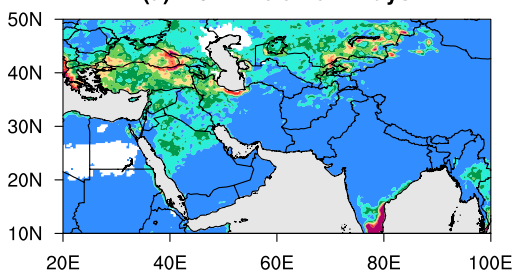

(d) FEB Extreme P Days

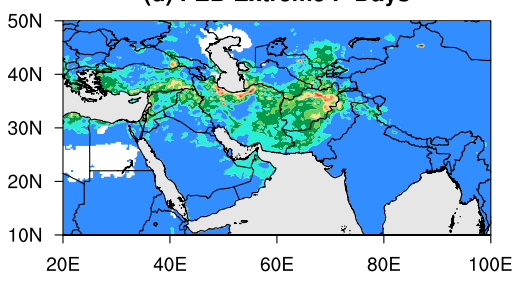

(b) DEC Extreme P Days

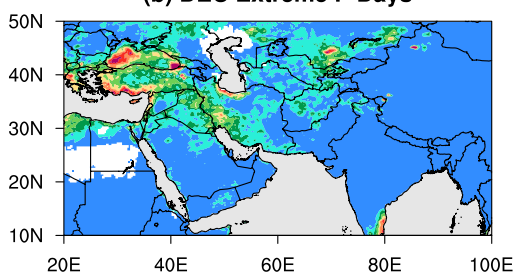

(e) MAR Extreme P Days

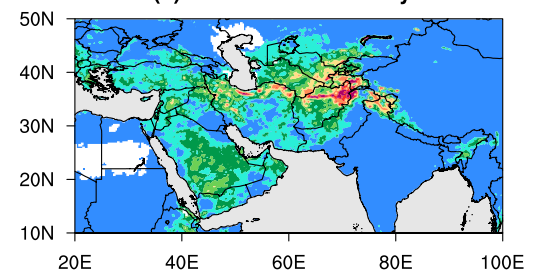

(c) JAN Extreme P Days

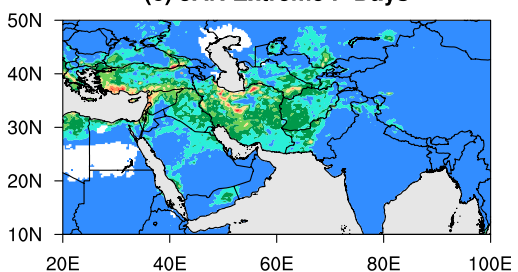

(f) APR Extreme P Days

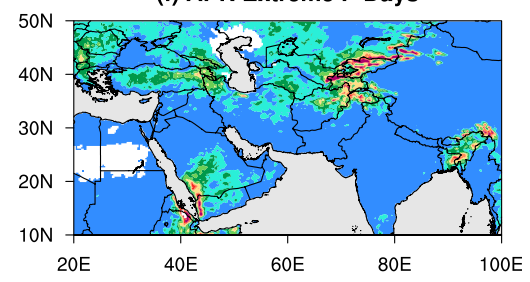

Extreme Precipitation Days When Neither MJO2-4 Nor MJO6-8 Are Met

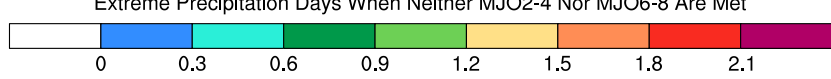

FIG. 5. Average number of extreme precipitation days when neither MJO2-4 nor MJO6-8 criteria are met. 
(a) November P on P Days

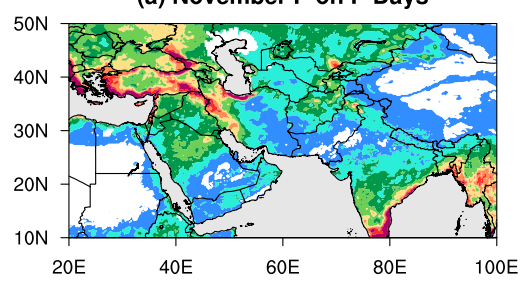

(d) February P on P Days

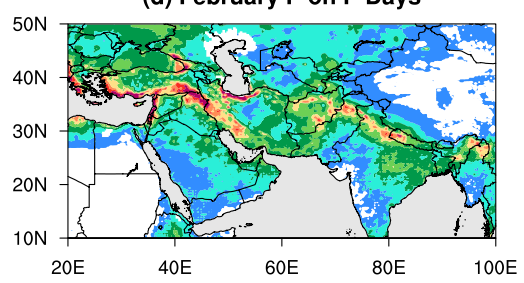

(b) December P on P Days

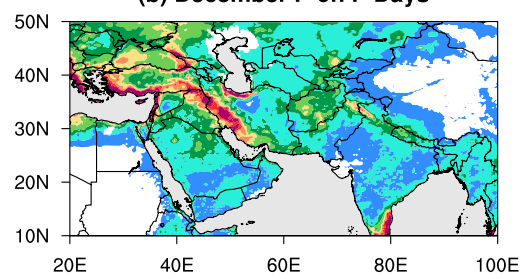

(e) March P on P Days

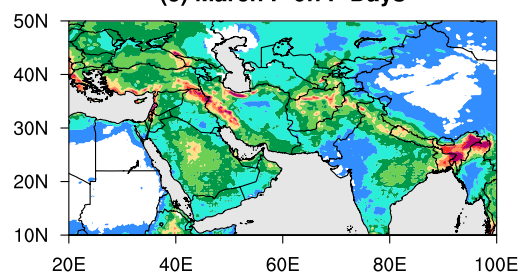

(c) January $P$ on P Days

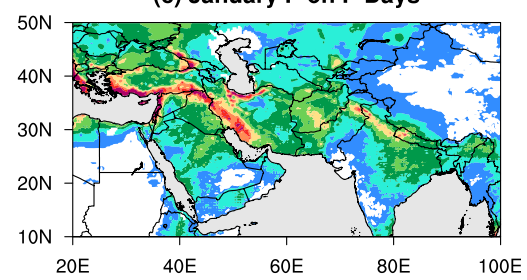

(f) April P on P Days

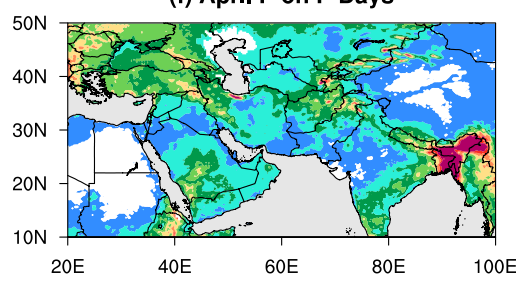

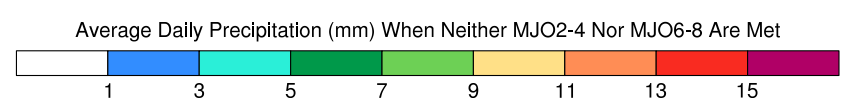

FIG. 6. Average precipitation (mm) on a precipitation day when neither MJO2-4 nor MJO6-8 criteria are met.

strongest area-averaged integrated vapor transport flux across the domain (not shown). Noteworthy aspects of extreme precipitation days during March include a near doubling of extreme precipitation days relative to February over the entire Arabian Peninsula and the mountains of High Asia, including the Pamir and Hindu Kush, likely due to concomitant strong upperlevel dynamics and more available moisture than in midwinter. The number of extreme precipitation days greatly decreases during April across almost all of the region, highlighted by a lifting of the pattern to the north, likely due to the weakened jet over MESW and increasing available moisture at higher latitudes in spring.

The amount of precipitation that falls on a precipitation day throughout the MESW during inactive MJO varies widely in space and time (Fig. 6), presumably as a result of how moisture-bearing low-pressure areas interact with the topography as those storms move from west to east across the region (Martyn 1992). During November and December, the maximum in precipitation on a precipitation day over MESW is found over Turkey, the Caucasus, and the northern Zagros on the windward side of high topography. The pattern of precipitation on precipitation days shifts southward during the core wintertime months of January-March, highlighted by maximums over the Zagros Mountains along almost the entire western border of Iran and the orography over Afghanistan and Pakistan, including the Hindu Kush and Karakorum. As the rainy season over MESW winds down in April, the amount of precipitation on a precipitation day diminishes regionwide, with regional maximums isolated to the east over the Hindu Kush and Karakorum.

\section{b. MESW precipitation characteristics during enhanced Indian Ocean precipitation associated with MJO2-4}

MJO2-4 is related to statistically significant decreases in the number of precipitation days throughout MESW, highlighted by a notable evolution in the spatial pattern of the decreases across December-March (Figs. 7 and S3). November and April, however, share few similarities with respect to the pattern and magnitude of the precipitation-day decreases with December-March. During November, MJO2-4 is unrelated with any spatially coherent statistically significant changes in the number of precipitation days across the MESW. During April, MJO2-4 is related with statistically significant reductions in the number of precipitation days only over southern Iraq, Saudi Arabia, and western Yemen.

December-March are the core months during which the number of precipitation days across MESW are significantly decreased associated with MJO2-4 (Figs. 7b-e and S3b-e). The common area of precipitation-day decreases across each of these months surrounds the Persian Gulf, and includes northeastern Saudi Arabia, southern Iraq, and southwestern Iran. Outside of the Persian Gulf area, there is a clear evolution to the pattern in the reduction of the number of precipitation days during $\mathrm{MJO} 2-4$. This evolution is characterized by a shift in the reduction of precipitation days from northwest to southeast between DecemberJanuary and February-March. While February and 
(a) MJO2-4 NOV P Days Change

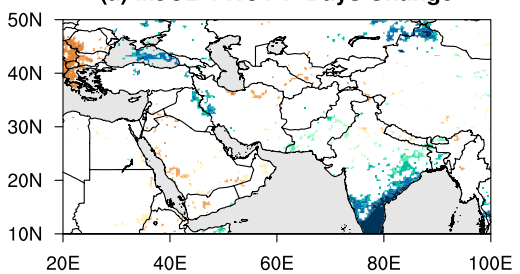

(d) MJO2-4 FEB P Days Change

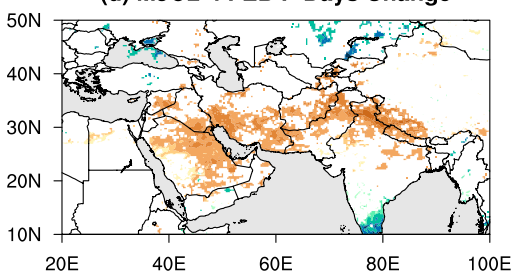

(b) MJO2-4 DEC P Days Change

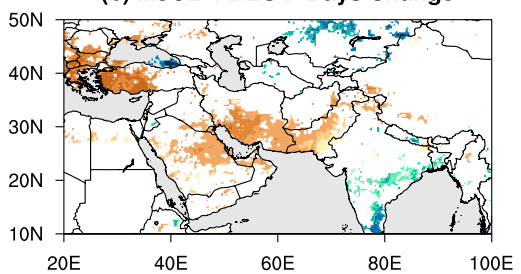

(e) MJO2-4 MAR P Days Change

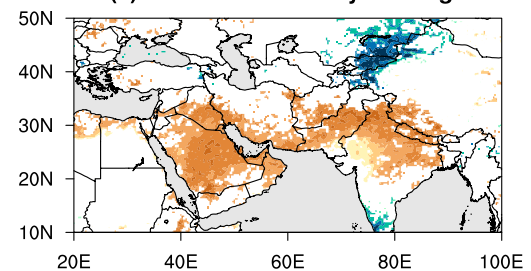

(c) MJO2-4 JAN P Days Change

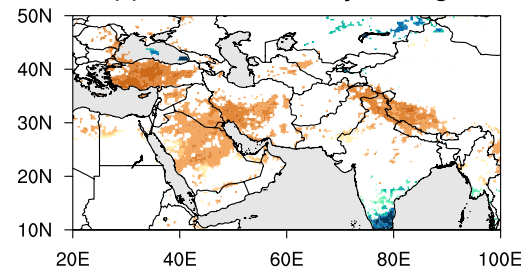

(f) MJO2-4 APR P Days Change

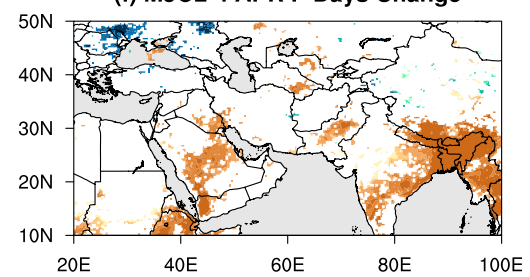

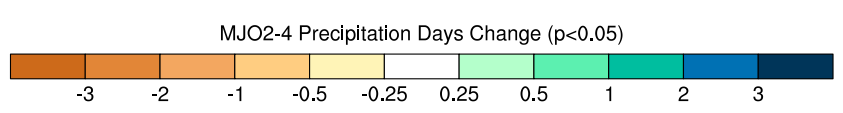

FIG. 7. Change in the average number of precipitation days when MJO2-4 criteria are met using RMM. Changes are significant at $p<0.05$.

March share very similar change patterns in the number of precipitation days during $\mathrm{MJO} 2-4$, the magnitude of the reductions are much stronger during March.

MJO2-4 is also related with statistically significant decreases in the number of extreme precipitation days throughout MESW during November-April (Figs. 8 and S4), taking on a broadly similar spatiotemporal evolution as the patterns in the reductions of the number of precipitation days south of $35^{\circ} \mathrm{N}$ (cf. Figs. 8 and 7). The simultaneous reduction in the number of extreme precipitation days and precipitation days associated with
MJO2-4 is not surprising since fewer precipitation days provide fewer opportunities for precipitation extremes.

December-March are the core months during which the number of extreme precipitation days are reduced associated with MJO2-4, and November and April share few similarities with respect to the pattern and magnitude of decreases of such days with those core months (Figs. 8 and S4). Widespread reductions in the number of extreme precipitation days south of $35^{\circ} \mathrm{N}$, extending from Saudi Arabia to Pakistan, associated with MJO2-4 are prominent during December-March (a) MJO2-4 NOV Extreme P Day Change

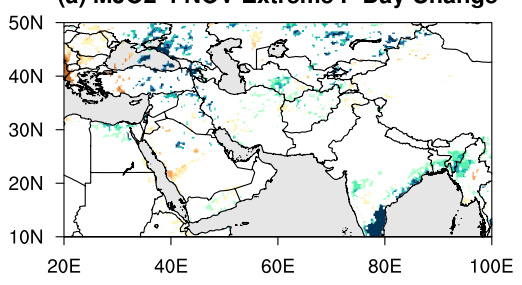

(d) MJO2-4 FEB Extreme P Day Change

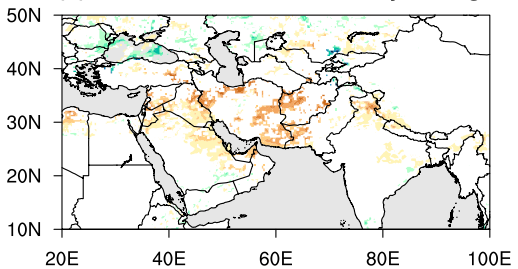

(b) MJO2-4 DEC Extreme P Day Change

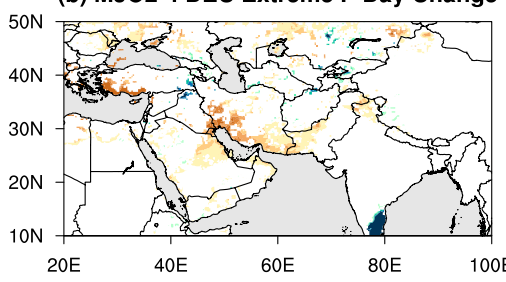

(e) MJO2-4 MAR Extreme P Day Change

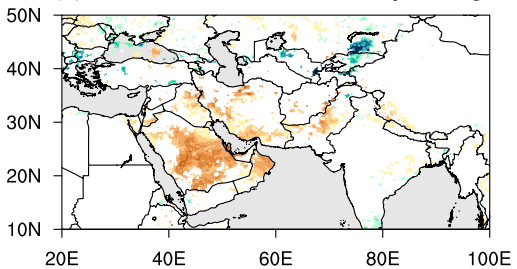

(c) MJO2-4 JAN Extreme P Day Change

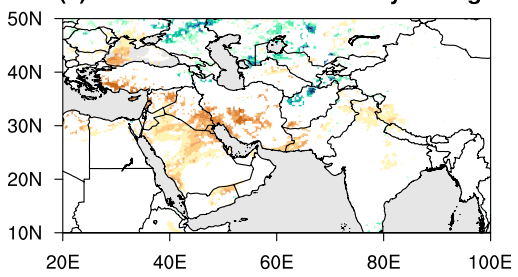

(f) MJO2-4 APR Extreme P Day Change

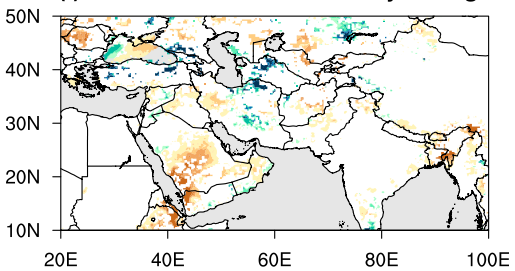

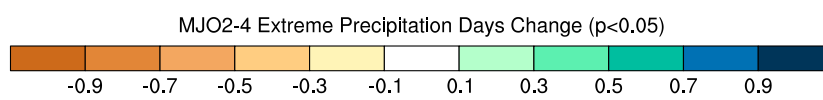

FIG. 8. Change in average number of extreme precipitation days when MJO2-4 criteria are met using RMM. Changes are significant at $p<0.05$. 
(a) MJO2-4 NOV P on P Day Diff

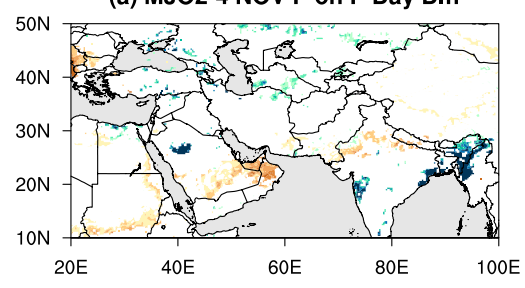

(d) MJO2-4 FEB P on P Day Diff

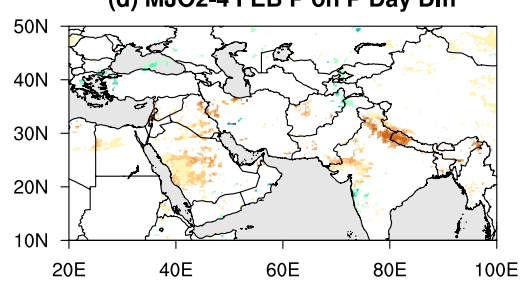

(b) MJO2-4 DEC P on P Day Diff

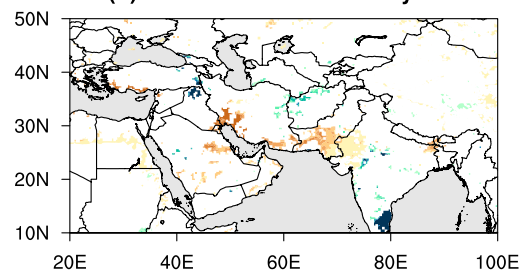

(e) MJO2-4 MAR P on P Day Diff

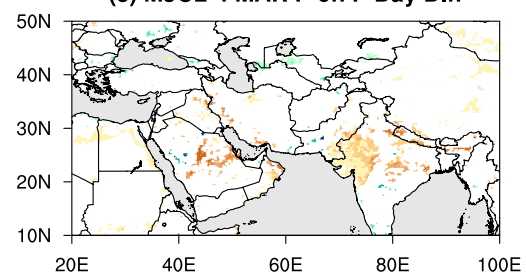

(c) MJO2-4 JAN P on P Day Diff

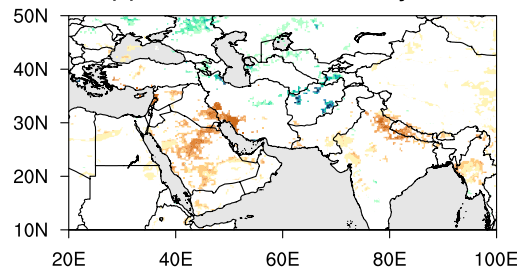

(f) MJO2-4 APR P on P Day Diff

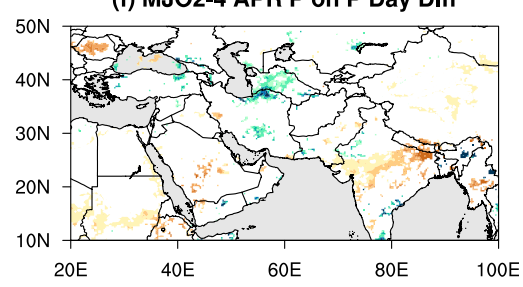

MJO2-4 Daily Precipitation (mm) on Precipitation Days Change $(\mathrm{p}<0.05)$
\begin{tabular}{|l|l|l|l|l|l|l|l|l|l|}
\hline & & & & & & & & & \\
\hline
\end{tabular}

FIG. 9. Change in average precipitation $(\mathrm{mm})$ on a precipitation day when MJO2-4 criteria are met using RMM. Changes are significant at $p<0.05$.

(Figs. 8 and S4). Similar to how the pattern of the number of precipitation days evolves during DecemberMarch associated with MJO2-4, the pattern of extreme precipitation days also expands from west to east between December-January and February-March. During December-January, reductions in the number of extreme precipitation days are found mostly around the Persian Gulf, including Saudi Arabia, Iraq, and southern Iran. During February-March, the spatial breadth in the reductions in the number of extreme precipitation days expands eastward and also increases in magnitude, extending from Saudi Arabia to Pakistan. March is the month during which the number of extreme precipitation days is most greatly reduced regionwide associated with $\mathrm{MJO} 2-4$, especially so across Saudi Arabia and Oman.

While preferred patterns in the spatiotemporal evolution of the reductions of the number of precipitation days and extreme precipitation days emerge during boreal winter across MESW associated with $\mathrm{MJO} 2-4$, somewhat surprisingly, MJO2-4 is not closely related with widespread spatially coherent and statistically significant change patterns in the amount of precipitation on a precipitation day (Figs. 9 and S5). Significant reductions in precipitation accumulation on precipitation days are isolated mostly over the southernmost coastal portions of southwest Asia during the months of December-March. During December and January, the Persian Gulf is the area in which the most notable precipitation accumulation decreases reside, while during February-March, the most notable precipitation accumulation decreases reside over Saudi Arabia only.
The average atmospheric circulation during MJO2-4 promotes an environment that is conducive for decreases in precipitation days and extreme precipitation days during December-March (Figs. 10 and 11). The atmospheric circulation anomalies for each month during MJO2-4 are broadly similar to the previously identified circulations for November-April in aggregate (e.g., Barlow et al. 2005, 2007; Hoell et al. 2012), specifically, the excitation of upper-tropospheric high pressure over subtropical Africa and Asia, anomalous midtropospheric downward motion, and a reduced flux of moisture into the MESW. By contrast, November and April are dissimilar from December-March in that high pressure, and consequently, changes in precipitation characteristics over MESW, are not related with MJO24 (Figs. 10a,f and 11a,f).

Upper-tropospheric high pressure and anomalous midtropospheric downward motion over the MESW are consistent features during MJO2-4 from December to March (Figs. 10b-e). The orientation and zonal and meridional extents of the high-pressure area are somewhat different from month to month, which in turn is related with the patterns of anomalous downward motion. During December, the high pressure has more of a southwest-to-northeast component to its orientation and a shorter zonal extent than JanuaryMarch, which results in a weaker and more concentrated area of anomalous downward motion over the southern extents of the MESW. During January-March, the high pressure extends from northern Africa to China and is nearly zonal, which is related with enhanced downward motion across the areas in which the number 
(a) NOV MJO2-4

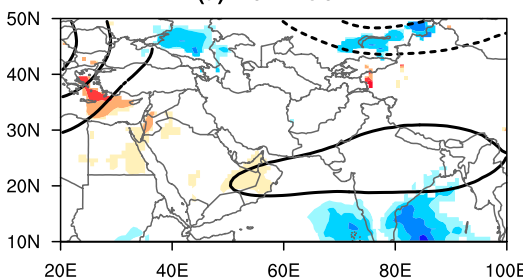

(d) FEB MJO2-4

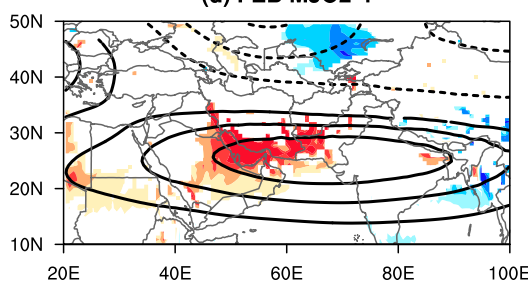

(b) DEC MJO2-4

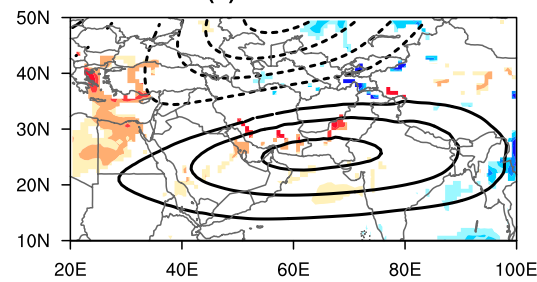

(e) MAR MJO2-4

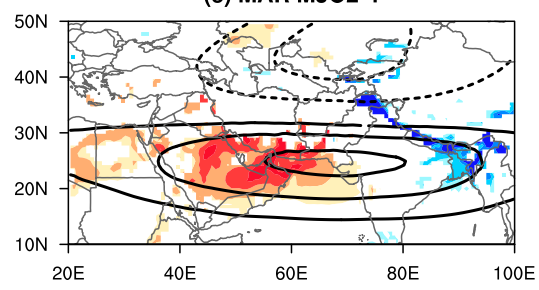

(c) JAN MJO2-4

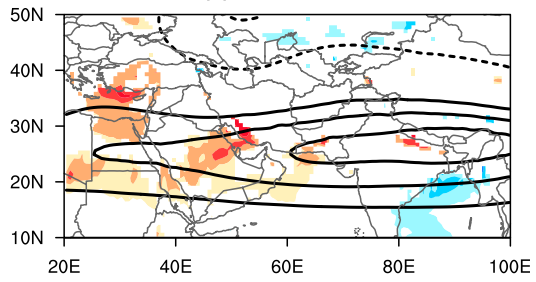

(f) APR MJO2-4

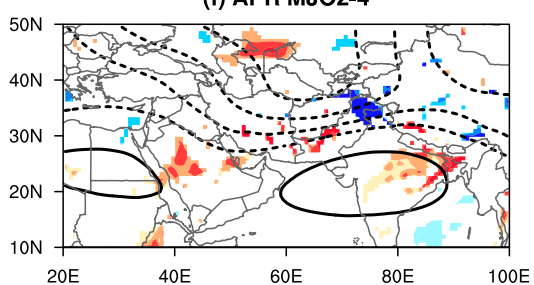

$500 \mathrm{hPa}$ Vertical Velocity Anomaly $\left(\mathrm{Pa} \mathrm{s}^{-1}\right)(\mathrm{p}<0.05)$

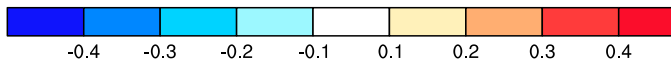

FIG. 10. Change in 200-hPa geopotential height (contours; m) and 500-hPa-pressure vertical velocity (shading; Pa s ${ }^{-1}$ ) when MJO2-4 criteria are met using RMM. Geopotential height is contoured every $200 \mathrm{~m}$ and negative values are dashed. Changes are significant at $p<0.05$.

of precipitation days are reduced (Fig. 7). This large-scale circulation anomaly over the climatological position of the jet also shifts the upper-level wind maxima northward and intensifies it, resulting in strong ascending motions in regions of high topography in the northeast portion of the domain and explaining the lack of precipitation reduction in that region.
The changes in the large-scale atmospheric circulation during MJO2-4 across December-March modify the local convergence and flux of vertically integrated moisture into and out of the MESW (Figs. 11b-e). While the patterns during December-March somewhat vary, anomalous northeasterly and northerly vertically integrated moisture flux reduce the amount of moisture (a) NOV MJO2-4

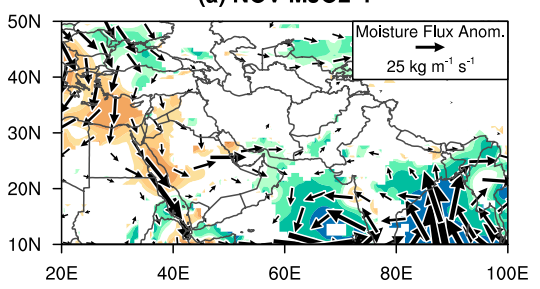

(d) FEB MJO2-4

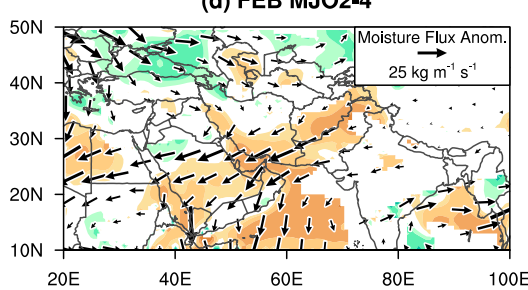

(b) DEC MJO2-4

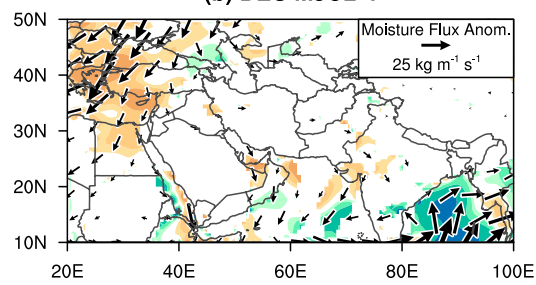

(e) MAR MJO2-4

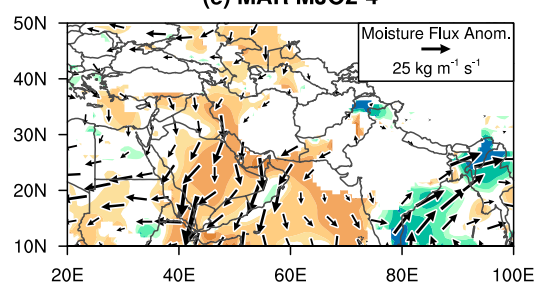

(c) JAN MJO2-4

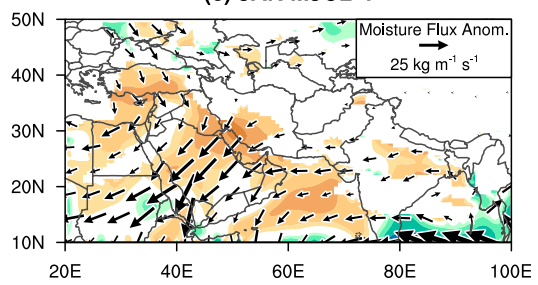

(f) APR MJO2-4

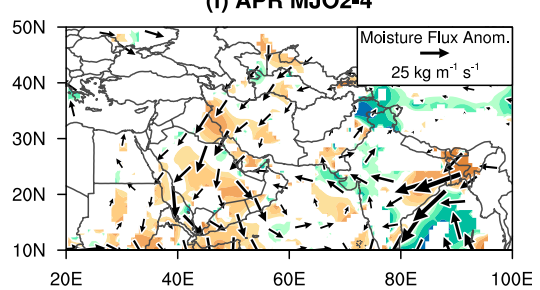

Vertically Integrated Moisture Flux Divergence Anomaly $\left(\mathrm{mm} \mathrm{month}^{-1}\right)(\mathrm{p}<0.05)$

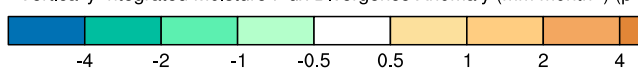

FIG. 11. Change in vertically integrated moisture flux divergence anomaly (shading; $\mathrm{mm} \mathrm{month}^{-1}$ ) and vertically integrated moisture flux (vectors; $\mathrm{kg} \mathrm{m}^{-1} \mathrm{~s}^{-1}$ ) when MJO2-4 criteria are met using RMM. Changes are significant at $p<0.05$. 
(a) MJO6-8 NOV P Days Change

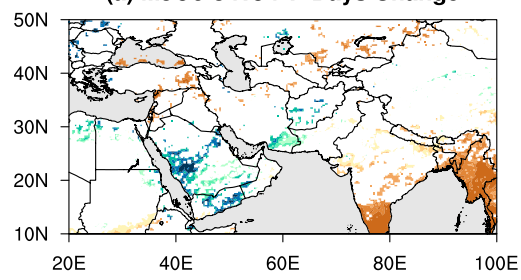

(d) MJO6-8 FEB P Days Change

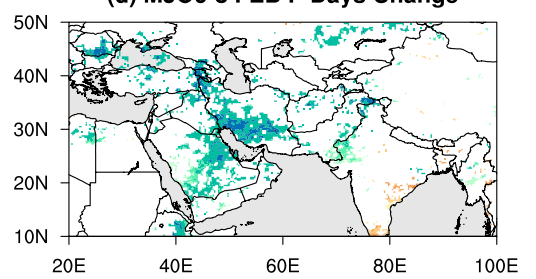

(b) MJ06-8 DEC P Days Change

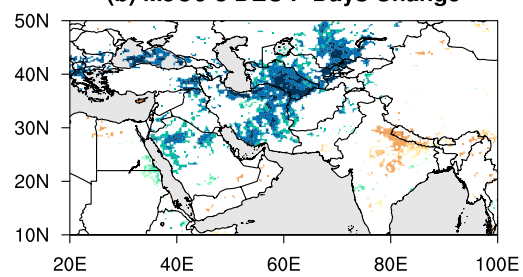

(e) MJO6-8 MAR P Days Change

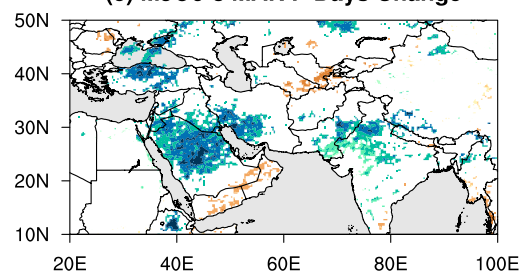

(c) MJ06-8 JAN P Days Change

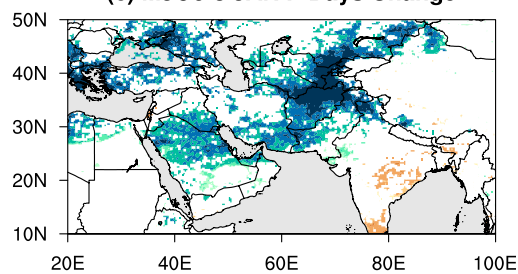

(f) MJO6-8 APR P Days Change

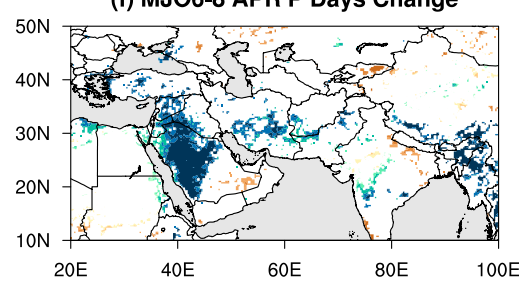

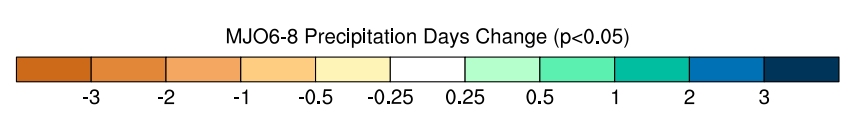

FIG. 12. Change in average number of precipitation days when MJO6-8 criteria are met using RMM. Changes are significant at $p<0.05$.

available for precipitation over the MESW, and largescale subsidence diminishes lifting of that moisture.

\section{c. MESW precipitation characteristics during reduced Indian Ocean precipitation associated with MJO6-8}

MJO6-8 is related with widespread statistically significant increases in the number of precipitation days throughout the MESW, highlighted by a notable northto-south dichotomy in the pattern of precipitation-day changes between core wintertime months of DecemberJanuary and late winter and early springtime months of February-April (Figs. 12 and S8). November shares the least similarity in terms of the pattern and magnitude of precipitation-day decreases with the other months. The largest regionwide increases in the number of precipitation days during MJO6-8 occur during DecemberJanuary, with most notable increases over northernmost portions of MESW (Figs. 12 and S8). The pattern of the increases in the number of precipitation days during MJO6-8 for December-January over these northernmost areas of MESW starkly contrasts the pattern of the decreases in the number of precipitation days during MJO2-4 for those same months, suggesting possible nonlinear behaviors in the regional relationship with the MJO. Also important during January, increases in the number of precipitation days begins to emerge over southern portions of the MESW during MJO6-8. February-April are the core months during which the number of precipitation days across southern MESW are significantly increased associated with MJO6-8. The largest such increases are found in a coherent spatial pattern that surrounds the Persian Gulf, composed of the most notable increases across Saudi Arabia, Iraq, and Iran.

MJO6-8 is also related with statistically significant changes in the number of extreme precipitation days across MESW during November-April (Figs. 13 and S9), but the patterns of such changes do not necessarily follow the patterns of the regionwide increases in the number of precipitation days (Fig. 12). The lack of similarities in the spatial patterns and their temporal evolution between extreme precipitation days and the number of precipitation days during MJO6-8 (cf. Figs. 13 and 12) starkly contrasts the similarities in the spatiotemporal evolution of the same patterns during MJO2-4 (cf. Figs. 8 and 7). The spatial patterns of extreme precipitation days during March and April are so spatially incoherent and temporally variable as to infer a lack of systematic forcing of extreme events by the MJO. MJO6-8 is not closely related with widespread spatially coherent and statistically significant change patterns in the amount of precipitation that falls on a precipitation day throughout November-April (Figs. 14 and S10).

The average atmospheric circulation during MJO6-8 promotes an environment that is conducive for increases in precipitation days and extreme precipitation days for each month during November-April (Figs. 15 and 16). MJO6-8 is related with the excitation of anomalous upper-tropospheric low pressure over subtropical Africa and Asia, anomalous midtropospheric upward motion, 
(a) MJO6-8 NOV Extreme P Day Change

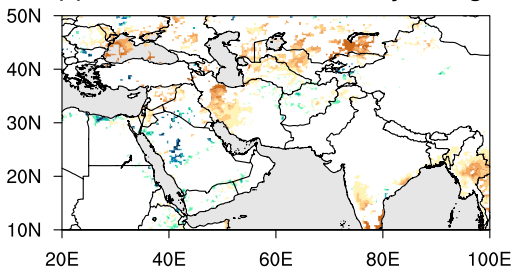

(d) MJO6-8 FEB Extreme P Day Change

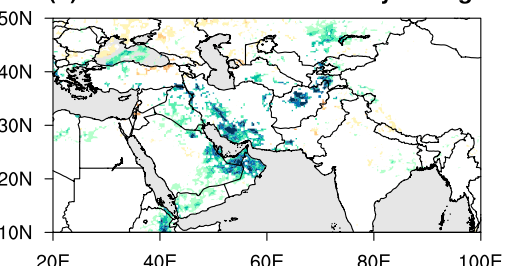

(b) MJO6-8 DEC Extreme P Day Change

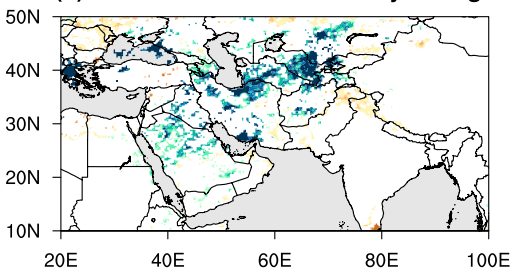

(e) MJO6-8 MAR Extreme P Day Change

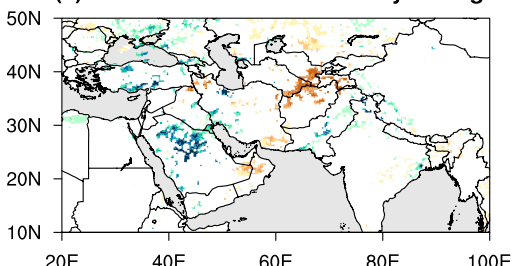

(c) MJO6-8 JAN Extreme P Day Change

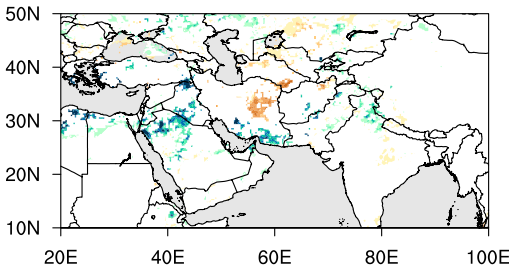

(f) MJ06-8 APR Extreme P Day Change

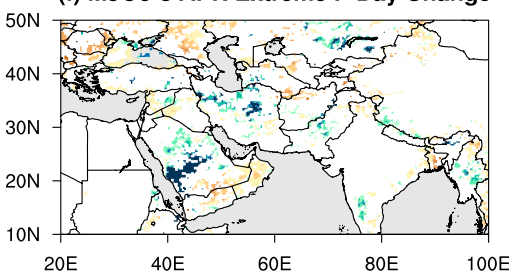

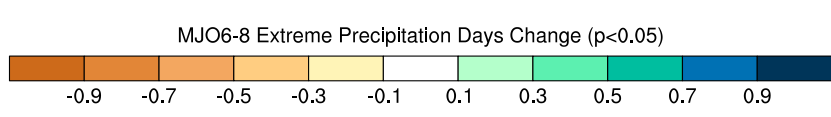

FIG. 13. Change in average number of extreme precipitation days when MJO6-8 criteria are met using RMM. Changes are significant at

$$
p<0.05 \text {. }
$$

and an enhanced flux of vertically integrated moisture into the MESW. However, important month-to-month differences in the spatial patterns of the atmospheric circulation are linked with differences in the spatial patterns of increases in precipitation days and extreme precipitation days.

The month-to-month differences in the atmospheric circulation during MJO6-8 are most apparent in the anomalous $200-\mathrm{hPa}$ low pressure over the MESW (Fig. 15; contours). The differences in the orientation, magnitude, and zonal extent of the anomalous low is in turn related with differences in anomalous vertical motions (Fig. 15; shading) and moisture fluxes into and out of the MESW (Fig. 16). The zonal extents of the anomalous low are smallest during November and April, which in turn is related with localized changes in MESW vertical motions, moisture fluxes, and changes in precipitation characteristics. By contrast, the zonal extents of the anomalous low are broad during December-March, extending (a) MJO6-8 NOV P on P Day Change

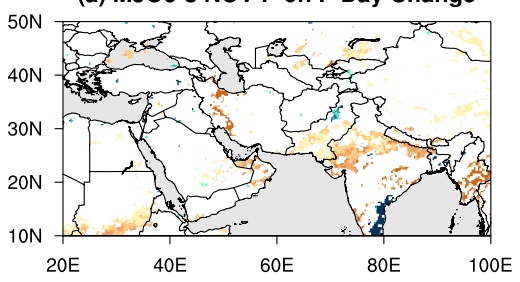

(d) MJO6-8 FEB P on P Day Change

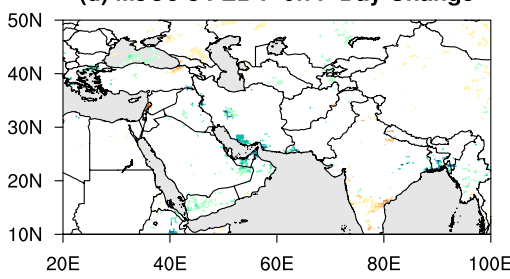

(b) MJO6-8 DEC P on P Day Change

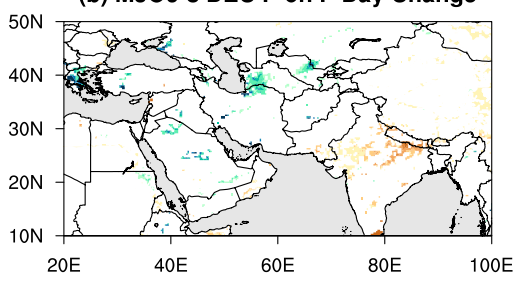

(e) MJO6-8 MAR P on P Day Change

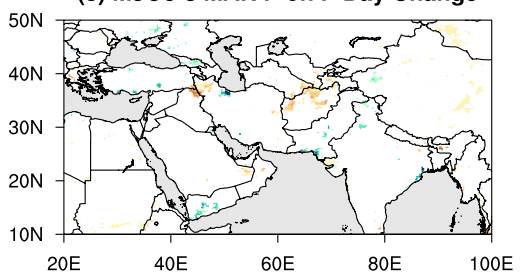

(c) MJO6-8 JAN P on P Day Change

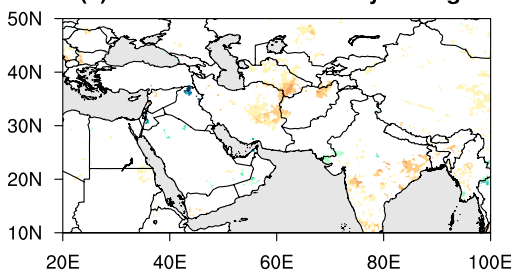

(f) MJO6-8 APR P on P Day Change

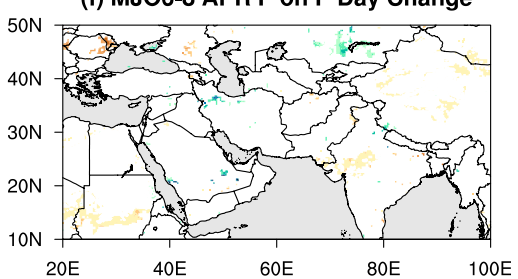

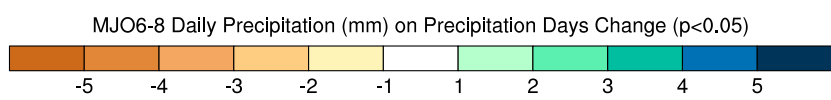

FIG. 14. Change in average precipitation $(\mathrm{mm})$ on a precipitation day when MJO6-8 criteria are met using RMM. Changes are significant at $p<0.05$. 
(a) NOV MJO6-8

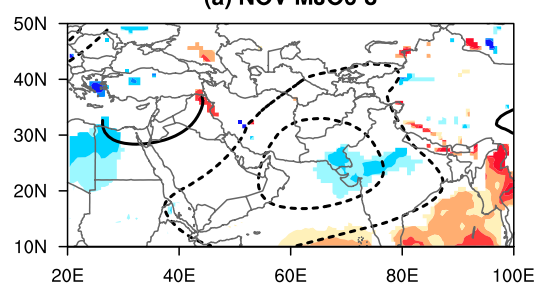

(d) FEB MJO6-8

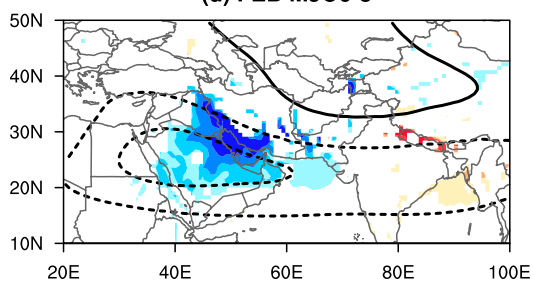

(b) DEC MJO6-8

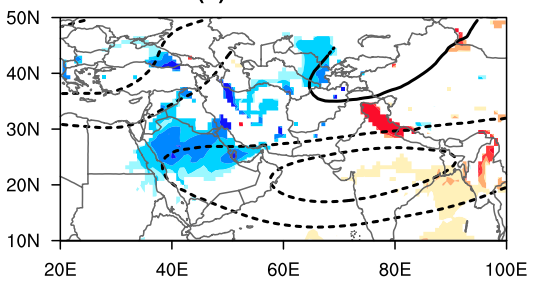

(e) MAR MJO6-8

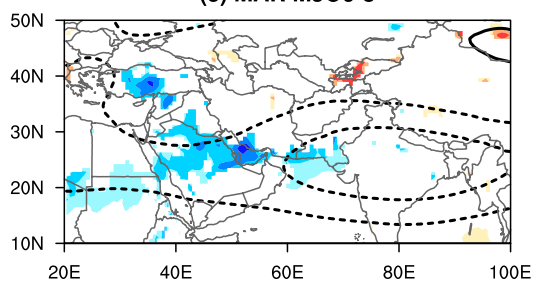

(c) JAN MJO6-8

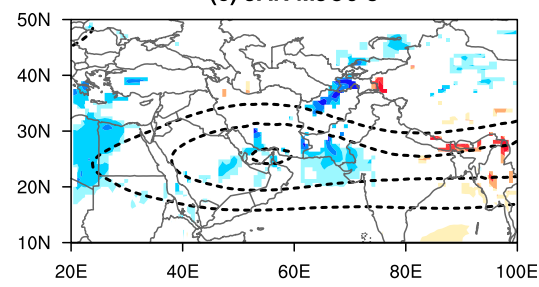

(f) APR MJO6-8

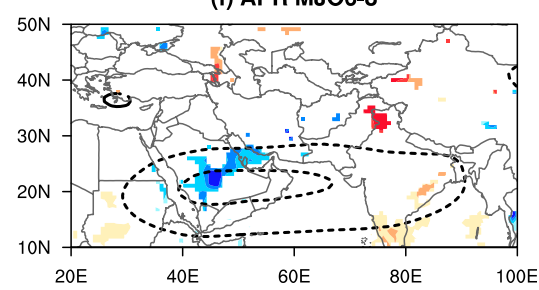

$500 \mathrm{hPa}$ Vertical Velocity Anomaly $\left(\mathrm{Pa} \mathrm{s}^{-1}\right)(\mathrm{p}<0.05)$

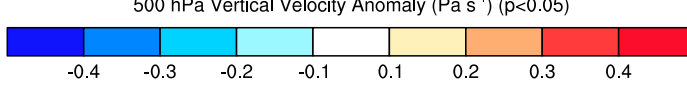

FIG. 15. Change in 200-hPa geopotential height (contours; m) and 500-hPa-pressure vertical velocity (shading; Pa s ${ }^{-1}$ ) when MJO6-8 criteria are met using RMM. Geopotential height is contoured every $200 \mathrm{~m}$ and negative values are dashed. Changes are significant at $p<0.05$.

from northern Africa to China, which is in turn related with widespread changes in vertical motions and moisture fluxes into and out of the MESW.

\section{Summary and discussion}

We examined Middle East and southwest Asia (MESW) precipitation characteristics during periods of enhanced or reduced tropical eastern Indian Ocean precipitation associated with opposing phases of the Madden-Julian oscillation (MJO) using multiple estimates of both observed precipitation and MJO state during November-April 1981-2016 to provide a more robust assessment in this data-limited region. We considered the MJO relationship with daily precipitation in terms of both frequency and intensity measures and (a) NOV MJO6-8

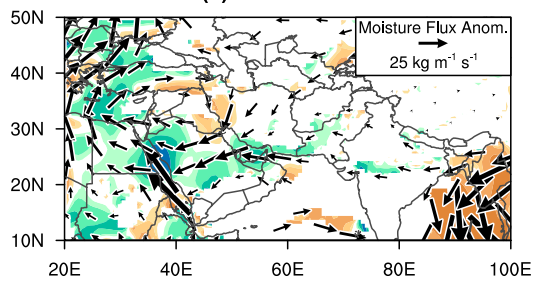

(d) FEB MJO6-8

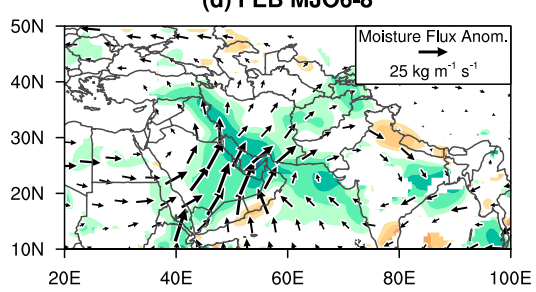

(b) DEC MJO6-8

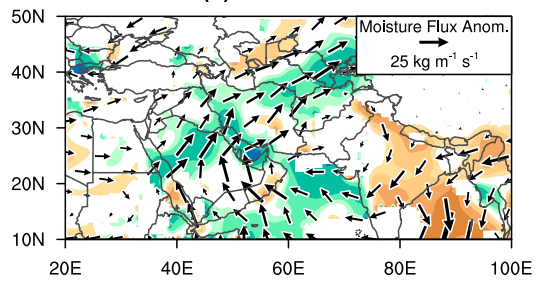

(e) MAR MJO6-8

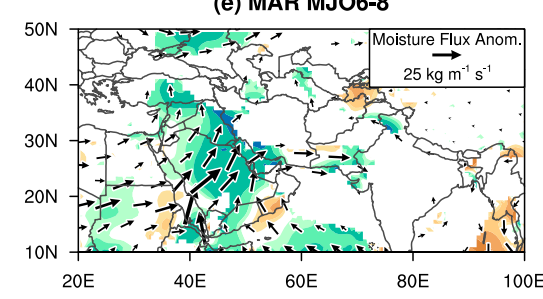

(c) JAN MJO6-8

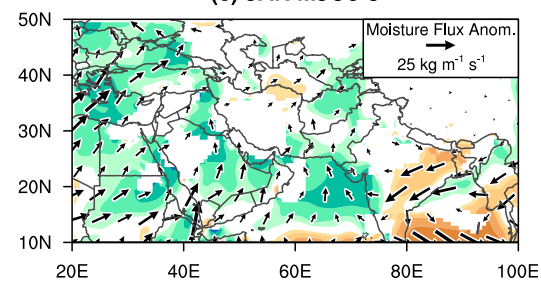

(f) APR MJO6-8

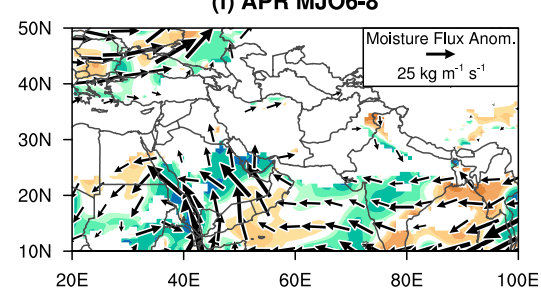

Vertically Integrated Moisture Flux Divergence Anomaly $\left(\mathrm{mm} \mathrm{month}^{-1}\right)(\mathrm{p}<0.05)$

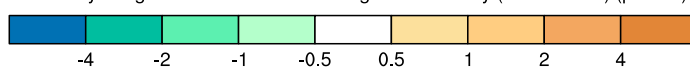

FIG. 16. Change in vertically integrated moisture flux divergence anomaly (shading; $\mathrm{mm} \mathrm{month}^{-1}$ ) and vertically integrated moisture flux (vectors; $\mathrm{kg} \mathrm{m}^{-1} \mathrm{~s}^{-1}$ ) when MJO6-8 criteria are met using RMM. Changes are significant at $p<0.05$. 
associated changes to the atmospheric circulation, and showed that there are large changes in the MJO influence on these characteristics over the course of the November-April wet season.

Changes in the atmospheric circulation during MJO24 promote an environment conducive for statistically significant decreases in the number of precipitation days and the number of extreme precipitation days, but somewhat surprisingly, not widespread spatially coherent changes in the amount of precipitation that falls on a precipitation day. Especially notable is the evolution in spatial patterns across December-March in the number of precipitation days and the number of extreme precipitation days over MESW during MJO2-4. The evolution is characterized by a shift in the reduction of precipitation days and extreme precipitation days from northeast to southwest between December-January and February-March. Notably over Afghanistan and Pakistan, the statistically significant changes occur during the climatologically rainiest two months of February and March. Despite this temporal evolution during December-March, the Persian Gulf and surrounding areas see consistent decreases in precipitation days and extreme precipitation days during each DecemberMarch month.

Changes in the atmospheric circulation during MJO68 promote an environment conducive for statistically significant increases in the number of precipitation days and the number of extreme precipitation, but not widespread changes in the amount of precipitation that falls on a precipitation day. Importantly, the spatial patterns of precipitation-day and extreme-precipitationday changes across MESW between MJO2-4 and MJO6-8 are not mirror images of one another, which is suggestive of potentially important nonlinearities in the MESW relationship with the MJO.

Superimposing these changes associated with $\mathrm{MJO} 2-$ 4 and MJO6-8 onto the background monthly climatology provides context to the observed changes in precipitation days. During November and April, considerably more moisture is present over MESW because of higher temperatures associated with the annual cycle of incoming solar radiation; however, dynamical forcing is at a premium as the temperature gradient in the upper troposphere is comparatively weak at this time. It appears that the additional moisture supplied to MESW by the influence of MJO6- 8 on anomalous vapor transport has little added benefit to precipitation processes during November and April. Contrastingly, during DecemberMarch the enhancement of available moisture to the region supplies the climatological storm track with much-needed moisture. Favorable conditions for largescale ascent are present over the southern portion of
MESW (Fig. 15), and although the anomalous upperlevel circulation weakens the subtropical jet, the region is comparatively more moisture limited than dynamics limited at that time of the year. Consequently, precipitation is enhanced during MJO6-8 in DecemberMarch as lift is still effectively generated, but includes additional moisture (Fig. 12). The converse is apparent during $\mathrm{MJO} 2-4$, when intensified dynamics on the northern extent of the region of large-scale subsidence (Fig. 10) are unable to generate a positive precipitation anomaly because of the exacerbated moisture limitation in that region in midwinter (Fig. 7). Continued research will specifically focus on month-to-month variability of MJO forcing and its interaction with the seasonal climatology of dynamic and thermodynamic mechanisms for precipitation over MESW in individual events.

These analyses also identified that the sensitivity to MJO phase was less apparent in terms of the number of extreme precipitation days and, in particular, the amount of precipitation on a precipitation day. It is possible that the MESW's position in a dynamically active (i.e., under the climatological position of the subtropical jet), yet moisture-limited (i.e., arid desert) regime creates an environment that can generate significant differences in the number of precipitation days through only incremental changes in available moisture according to MJO phase. However, with respect to extremes, these events are prototypically associated with western disturbances, which are stochastic in nature and benefit from a multitude of additional precipitation mechanisms (Cannon et al. 2017). Changes in moisture or dynamical forcing related to MJO phase are less likely to project a consistent response onto observed precipitation in these events, as there are also influences of microphysical, mesoscale, and synoptic-scale precipitation processes. This open question presents an important direction for future research toward understanding the response of MESW precipitation to MJO forcing and augmenting its potential predictability.

Different metrics of the MJO have been developed to highlight different characteristic behaviors of the MJO itself, which may motivate one to ask whether these different metrics suggest different MJO impacts on MESW precipitation. To that end, we calculated the number of precipitation days, the number of extreme precipitation days, and the amount of precipitation on a precipitation day over MESW associated with MJO2-4 and MJO6-8 using two MJO indices, RMM and OMI. RMM measures the MJO through a combination of OLR and circulation-based characteristics while OMI measures the MJO through only OLR characteristics. We found the results to be largely insensitive to the MJO estimate used despite the differing methodologies used 
to calculate the indices and the numbers of days that qualify for each MJO index.

Uncertainties in our results may also arise from the choice of precipitation dataset used to assess the relationship between the MJO and MESW precipitation. In this work, we primarily rely on the CHIRPS precipitation dataset, given that CHIRPS is well suited to simultaneously estimate precipitation over regions in which station observations are sparse and over regions in which station observations are numerous. To test the degree to which the choice of precipitation dataset introduces uncertainties into the interpretation of how MESW precipitation is related to the MJO, we reproduced our results using two other precipitation datasets, CHIRP and CPC-Unified, over Persian Gulf and Afghanistan-Pakistan subregions (Figs. S9 and S10).

We find that the MJO relationship with both Persian Gulf and Afghanistan-Pakistan daily precipitation comes through in all precipitation datasets, suggesting that our findings are largely insensitive to the choice of precipitation dataset. The shapes of the cumulative daily precipitation histograms over the Persian Gulf (Fig. S9; red box in Fig. S1) and Afghanistan-Pakistan (Fig. S10; purple box in Fig. S1) are similar, even if the absolute values are not, suggesting that precipitation extremes, dry days, wet days, and precipitation on precipitation days that we find are not sensitive to the choice of precipitation dataset. CHIRP, a satellite-only precipitation dataset, has a slightly different distribution than the other two, as evidenced by a steeper slope, indicating considerable low-intensity precipitation and a weak maximum precipitation. The likely reason behind this is that infrared precipitation estimates common to satellite-only precipitation products were developed to sense convection, and not orographic clouds common to MESW. Interestingly, CHIRPS, which blends both station data and the remotely sensed estimates of CHIRP, is more similar to the CPC-Unified station-only precipitation dataset than to CHIRP, demonstrating the notable effect of station data in the CHIRPS estimates.

Prior to our analysis, research linking the MJO and MESW precipitation had considered either NovemberApril in aggregate or smaller areas within MESW, thereby limiting the predictive information that the MJO provides for MESW throughout the course of the region's rainy season. To that end, our analysis fills an important knowledge gap on how MESW precipitation varies spatially throughout the course of the NovemberApril rainy season associated with the MJO. In addition to informing subseasonal precipitation prediction skill related with the $\mathrm{MJO}$, this analysis can also be used as a baseline from which we test apparent sensitivities of precipitation to the $\mathrm{MJO}$ in models, which is becoming increasingly important as initialized forecast systems improve MJO prediction.

Precipitation prediction skill improvements across MESW would likely reduce the loss of life and property (Agrawala et al. 2001) and the social and economic instability (Gall 2008) associated with extreme events on subseasonal to seasonal time scales. Early warning of a single precipitation event or in some cases a sequence of precipitation events would allow water managers to prepare for changes in the region's water resources and people to prepare their property accordingly. Likewise, early warning of a lack of precipitation events would allow farmers to prepare their rain-fed crops, water managers to conserve water, and aid organizations to mobilize food and water assistance programs.

Acknowledgments. The authors gratefully acknowledge support from the Famine Early Warning Systems Network, George Kiladis and Juliana Dias for providing the OMI index, and the thoughtful and constructive comments of three anonymous reviewers.

\section{REFERENCES}

Agrawala, S., M. Barlow, H. Cullen, and B. Lyon, 2001: The drought and humanitarian crisis in central and southwest Asia: A climate perspective. IRI Special Rep. 01-11, 24 pp.

Alvarez, M. S., C. S. Vera, G. N. Kiladis, and B. Liebmann, 2016: Influence of the Madden Julian oscillation on precipitation and surface air temperature in South America. Climate Dyn., 46, 245-262, https://doi.org/10.1007/s00382-015-2581-6.

Barlow, M., 2011: Africa and west Asia. Intraseasonal Variability in the Atmosphere-Ocean Climate System, W. K. M. Lau and D. E. Waliser, Eds., Springer Praxis, 477-493.

-, H. Cullen, and B. Lyon, 2002: Drought in central and southwest Asia: La Niña, the warm pool, and Indian Ocean precipitation. J. Climate, 15, 697-700, https://doi.org/10.1175/ 1520-0442(2002)015<0697:DICASA > 2.0.CO;2.

- M. Wheeler, B. Lyon, and H. Cullen, 2005: Modulation of daily precipitation over southwest Asia by the Madden-Julian oscillation. Mon. Wea. Rev., 133, 3579-3594, https://doi.org/ 10.1175/MWR3026.1.

_ A. Hoell, and F. Colby, 2007: Examining the wintertime response to tropical convection over the Indian Ocean by modifying convective heating in a full atmospheric model. Geophys. Res. Lett., 34, L19702, https://doi.org/10.1029/2007GL030043.

Berhane, F., and B. Zaitchik, 2014: Modulation of daily precipitation over East Africa by the Madden-Julian oscillation. J. Climate, 27, 6016-6034, https://doi.org/10.1175/ JCLI-D-13-00693.1.

,$- \ldots$, and H. S. Badr, 2015: The Madden-Julian oscillation's influence on spring rainy season precipitation over equatorial West Africa. J. Climate, 28, 8653-8672, https://doi.org/10.1175/ JCLI-D-14-00510.1.

Cannon, F., L. M. V. Carvalho, C. Jones, A. Hoell, J. Norris, G. N. Kiladis, and A. A. Tahir, 2017: The influence of tropical forcing on extreme winter precipitation in the western 
Himalaya. Climate Dyn., 48, 1213-1232, https://doi.org/10.1007/ s00382-016-3137-0.

Chen, M., W. Shi, P. Xie, V. B. S. Silva, V. E. Kousky, R. Wayne Higgins, and J. E. Janowiak, 2008: Assessing objective techniques for gauge-based analyses of global daily precipitation. J. Geophys. Res., 113, D04110, https://doi.org/10.1029/ 2007JD009132.

Dee, D. P., and Coauthors, 2011: The ERA-Interim reanalysis: Configuration and performance of the data assimilation system. Quart. J. Roy. Meteor. Soc., 137, 553-597, https://doi.org/ 10.1002/qj.828.

De Souza, E. B., and T. Ambrizzi, 2006: Modulation of the intraseasonal rainfall over tropical Brazil by the Madden-Julian oscillation. Int. J. Climatol., 26, 1759-1776, https://doi.org/ 10.1002/joc.1331.

Funk, C., and Coauthors, 2015: The climate hazards infrared precipitation with stations-A new environmental record for monitoring extremes. Sci. Data, 2, 150066, https://doi.org/ 10.1038/sdata.2015.66.

Gall, C., 2008: War and drought threaten Afghan food supply. New York Times, 18 September, A1, https://www.nytimes.com/2008/ 09/19/world/asia/19afghan.html.

Gill, A. E., 1980: Some simple solutions for heat-induced tropical circulation. Quart. J. Roy. Meteor. Soc., 106, 447-462, https:/ doi.org/10.1002/qj.49710644905.

Hoell, A., and C. Funk, 2013: The ENSO-related west Pacific sea surface temperature gradient. J. Climate, 26, 9545-9562, https://doi.org/10.1175/JCLI-D-12-00344.1.

—, M. Barlow, and R. Saini, 2012: The leading pattern of intraseasonal and interannual Indian Ocean precipitation variability and its relationship with Asian circulation during the boreal cold season. J. Climate, 25, 7509-7526, https://doi.org/ 10.1175/JCLI-D-11-00572.1.

- —, and — 2013: Intraseasonal and seasonal-tointerannual Indian Ocean convection and hemispheric teleconnections. J. Climate, 26, 8850-8867, https://doi.org/10.1175/ JCLI-D-12-00306.1.

— C. Funk, and M. Barlow, 2014: La Niña diversity and northwest Indian Ocean rim teleconnections. Climate Dyn., 43, 2707-2724, https://doi.org/10.1007/ s00382-014-2083-y.

,-- , and,$- 2015 \mathrm{a}$ : The forcing of southwestern Asia teleconnections by low-frequency sea surface temperature variability during boreal winter. J. Climate, 28, 1511-1526, https://doi.org/10.1175/JCLI-D-14-00344.1.

— S. Shukla, M. Barlow, F. Cannon, C. Kelley, and C. Funk, 2015b: The forcing of monthly precipitation variability over southwest Asia during the boreal cold season. J. Climate, 28, 7038-7056, https://doi.org/10.1175/JCLI-D-14-00757.1.

- M. Barlow, F. Cannon, and T. Xu, 2017: Oceanic origins of historical southwest Asia precipitation during the boreal cold season. J. Climate, 30, 2885-2903, https://doi.org/10.1175/ JCLI-D-16-0519.1.

,,-- T. Xu, and T. Zhang, 2018: Cold season southwest Asia precipitation sensitivity to El Niño-Southern Oscillation events. J. Climate, 31, 4463-4482, https://doi.org/10.1175/ JCLI-D-17-0456.1.

Jones, C., 2000: Occurrence of extreme precipitation events in California and relationships with the Madden-Julian oscillation. J. Climate, 13, 3576-3587, https://doi.org/10.1175/ 1520-0442(2000)013<3576:OOEPEI >2.0.CO;2.

—, and L. M. V. Carvalho, 2012: Spatial-intensity variations in extreme precipitation in the contiguous United States and the
Madden-Julian oscillation. J. Climate, 25, 4898-4913, https:// doi.org/10.1175/JCLI-D-11-00278.1.

_ , and —_, 2014: Sensitivity to Madden-Julian oscillation variations on heavy precipitation over the contiguous United States. Atmos. Res., 147-148, 10-26, https://doi.org/ 10.1016/j.atmosres.2014.05.002.

Kalnay, E., and Coauthors, 1996: The NCEP/NCAR 40-Year Reanalysis Project. Bull. Amer. Meteor. Soc., 77, 437-471, https:// doi.org/10.1175/1520-0477(1996)077<0437:TNYRP>2.0.CO;2.

Kiladis, G. N., J. Dias, K. H. Straub, M. C. Wheeler, S. N. Tulich, K. Kikuchi, K. M. Weickmann, and M. J. Ventrice, 2014: A comparison of OLR and circulation-based indices for tracking the MJO. Mon. Wea. Rev., 142, 1697-1715, https://doi.org/ 10.1175/MWR-D-13-00301.1.

Klotzbach, P. J., E. C. J. Oliver, R. D. Leeper, and C. J. Schreck, 2016: The relationship between the Madden-Julian oscillation (MJO) and southeastern New England snowfall. Mon. Wea. Rev., 144, 1355-1362, https://doi.org/10.1175/ MWR-D-15-0434.1.

Lau, K.-M., and P. H. Chan, 1983: Short-term climate variability and atmospheric teleconnections from satellite-observed outgoing longwave radiation. Part I: Simultaneous relationships. J. Atmos. Sci., 40, 2735-2750, https://doi.org/10.1175/ 1520-0469(1983)040<2735:STCVAA $>2.0$. CO;2.

Liebmann, B., 1987: Observed relationships between largescale tropical convection and the tropical circulation on subseasonal time scales during Northern Hemisphere winter. J. Atmos. Sci., 44, 2543-2561, https://doi.org/ 10.1175/1520-0469(1987)044<2543:ORBLST>2.0.CO;2.

- and C. A. Smith, 1996: Description of a complete (interpolated) outgoing longwave radiation dataset. Bull. Amer. Meteor. Soc., 77, 1275-1277.

Madden, R. A., and P. R. Julian, 1972: Description of globalscale circulation cells in the tropics with a 40-50 day period. J. Atmos. Sci., 29, 1109-1123, https://doi.org/10.1175/ 1520-0469(1972)029<1109:DOGSCC > 2.0.CO;2.

- , and - 1994: Observations of the 40-50-day tropical oscillation-A review. Mon. Wea. Rev., 122, 814-837, https:// doi.org/10.1175/1520-0493(1994)122<0814:OOTDTO>2.0.CO;2.

Matsuno, T., 1966: Quasi-geostrophic motions in the equatorial area. J. Meteor. Soc. Japan, 44, 25-43, https://doi.org/10.2151/ jmsj1965.44.1_25.

Mariotti, A., 2007: How ENSO impacts precipitation in southwest central Asia. Geophys. Res. Lett., 34, L16706, https://doi.org/ 10.1029/2007GL030078.

Martyn, D., 1992: Climates of the World. Developments in Atmospheric Science, Vol. 18, Elsevier, 436 pp.

Nazemosadat, M. J., and H. Ghaedamini, 2010: On the relationships between the Madden-Julian oscillation and precipitation variability in southern Iran and the Arabian Peninsula: Atmospheric circulation analysis. J. Climate, 23, 887-904, https://doi.org/10.1175/2009JCLI2141.1.

_ , and K. Shahgholian, 2017: Heavy precipitation in the southwest of Iran: Association with the Madden-Julian oscillation and synoptic scale analysis. Climate Dyn., 49, 3091-3109, https:// doi.org/10.1007/s00382-016-3496-6.

Pohl, B., and P. Camberlin, 2006: Influence of the Madden-Julian oscillation on East African rainfall. I: Intraseasonal variability and regional dependency. Quart. J. Roy. Meteor. Soc., 132, 2521-2539, https://doi.org/10.1256/qj.05.104.

, Y. Richard, and N. Fauchereau, 2007: Influence of the MaddenJulian oscillation on southern African summer rainfall. J. Climate, 20, 4227-4242, https://doi.org/10.1175/JCLI4231.1. 
Shimizu, M. H., and T. Ambrizzi, 2016: MJO influence on ENSO effects in precipitation and temperature over South America. Theor. Appl. Climatol., 124, 291-301, https://doi.org/10.1007/ s00704-015-1421-2.

, — - and B. Liebmann, 2017: Extreme precipitation events and their relationship with ENSO and MJO phases over northern South America. Int. J. Climatol., 37, 2977-2989, https://doi.org/10.1002/joc.4893.

Sossa, A., B. Liebmann, I. Bladé, D. Allured, H. H. Hendon, P. Peterson, and A. Hoell, 2017: Statistical connection between the Madden-Julian oscillation and large daily precipitation events in West Africa. J. Climate, 30, 1999-2010, https://doi.org/ 10.1175/JCLI-D-16-0144.1.

Wheeler, M. C., and H. H. Hendon, 2004: An all-season real-time multivariate MJO index: Development of an index for monitoring and prediction. Mon. Wea. Rev., 132, 1917-1932, https://doi.org/ 10.1175/1520-0493(2004)132<1917:AARMMI>2.0.CO;2.

,-- S. Cleland, H. Meinke, and A. Donald, 2009: Impacts of the Madden-Julian oscillation on Australian rainfall and circulation. J. Climate, 22, 1482-1498, https://doi.org/10.1175/2008JCLI2595.1. Zhang, C., 2005: Madden-Julian oscillation. Rev. Geophys., 43, RG2003, https://doi.org/10.1029/2004RG000158. 